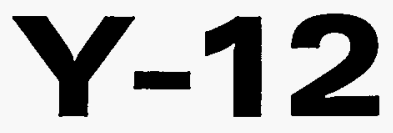

\section{OAK RIDGE $\mathrm{Y}-12$ PLANT}

MAETUN MARIETTA

\section{A CONTINUOUS AUTOMATED VAULT INVENTORY SYSTEM (CAVIS) FOR ACCOUNTABILITY MONITORING OF STORED NUCLEAR MATERIALS}

C. A. Pickeit, S. A. Wallace Development Division

\author{
T. A. Gafford \\ Defense Programs
}

B. W. Moran, M. A. Barham National Security Program Office

D. P. Hutchinson, L. C. Maxey, R. N. Nodine, M. L. Simpson, J. A. Williams I\&C Division, ORNL

\author{
J. K. Jordan, J. D. Muhs, D. B. Smith \\ Engineering Technology Division - ORNL
}

December 8, 1994

\section{Prepared by the} Oak Ridge Y-12 Plant managed by MARTIN MARIETTA ENERGY SYSTEMS, INC. for the

U.S. DEPARTMENT OF ENERGY under contract DE-AC05-84OR21400

\section{MANAGED BY}

MARTIN MARIETTA ENERGY SYSTEMS, INC.

FOR THE UNITED STATES

DEPARTMENT OF ENERGY

UCN-13672 (2 10-60) 


\section{DISCLAIMER}

This report was prepared as an account of work sponsored by an agency of the United States Government. Neither the United States Government nor any agency thereof, nor any of their employees, make any warranty, express or implied, or assumes any legal liability or responsibility for the accuracy, completeness, or usefulness of any information, apparatus, product, or process disclosed, or represents that its use would not infringe privately owned rights. Reference herein to any specific commercial product, process, or service by trade name, trademark, manufacturer, or otherwise does not necessarily constitute or imply its endorsement, recommendation, or favoring by the United States Government or any agency thereof. The views and opinions of authors expressed herein do not necessarily state or refiect those of the United States Government or any agency thereof. 


\section{DISCLAIMER}

Portions of this document may be illegible in electronic image products. Images are produced from the best available original document. 


\section{TABLE OF CONTENTS}

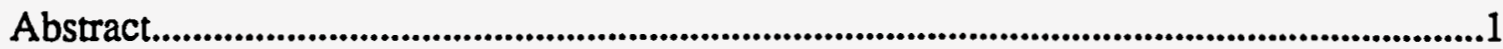

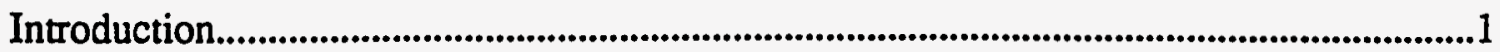

The Oak Ridge Y-12 Plant .............................................................................................................

CAVIS Sensor Descriptions....................................................................................................2

A. Optical Fiber Based Weight Measurement System .................................................2

1. Weight Sensor Description ..........................................................................3

2. Weight Sensor Performance and Costs ...................................................6

3. Future Developments for Weight Sensors ......................................................6

B. Fiber and Scintillator Technology (FAST) Detectors for Gamma and Neutron Flux Measurement ..........................................................................................6

1. FAST Overview ..................................................................................................6

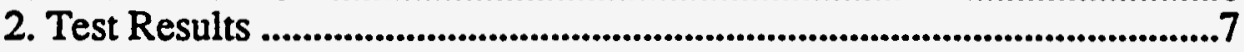

C. Silicon PIN Diode with Discriminating Electronics ...............................................9

1. Determining Relative Enrichments of U235 from Stored Items .................9

D. Scintillator - Photosensor Gamma Sensing Technology .......................................11

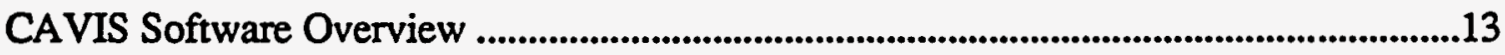

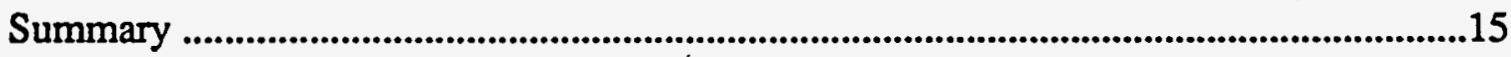

Acknowledgments .......................................................................................................................15

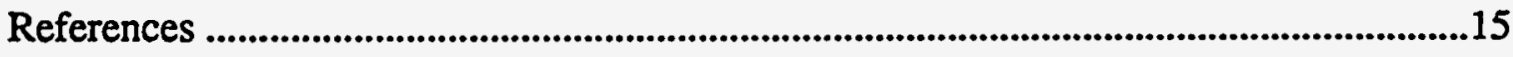

Appendices ................................................................................................................16

DISTRIBUTION OF THIS DOCUMENT IS UNLIMITEO w 


\title{
A Continuous Automated Vault Inventory System (CAVIS) for Accountability Monitoring of Stored Nuclear Materials
}

\author{
Chris A. Pickett, M. A. Barham. Thomas A. Gafford. Donald P. Hutchinson, John K. Jordan, \\ L. C. Maxey, Bruce W. Moran, Jeffery Muhs, Robert Nodine, Marc L. Simpson, \\ D. Barton Smith, Steven A. Waliace. Joe A. Williams \\ Martin Marietta Energy Systems \\ Oak Ridge, Tennessee 37831
}

\begin{abstract}
Nearly all facilities that store hazardous (radioactive or nonradioactive) materials must comply with prevailing federal. state, and local laws. These laws usually have components that require periodic physical inspections to insure that all materials remain safely and securely stored. The inspections are generally labor intensive, slow, put personnel at risk, and only find anomalies after they have occurred. The system described in this paper was developed for monitoring stored nuclear materials resulting from weapons dismantlement, but its applications extend to any storage facility that meets the above criteria.
\end{abstract}

The traditional special nuclear material (SNM) accountability programs, that are currently used within most of the Department of Energy (DOE) complex, require the physical entry of highly trained personnel into SNM storage vaults. This imposes the need for additional security measures, which typically mandate that extra security personnel be present while SNM inventories are performed. These requirements increase labor costs and put additional personnel at risk to radiation exposure. In some cases, individuals have received radiation exposure equivalent to the annual maximum during just one inventory verification!

With increasing overhead costs, the current system is rapidly becoming too expensive to operate, the need for an automated method of inventory verification is evident. The Continuous Automated Vault Inventory System (CAVIS) described in this paper was designed and prototyped as a low cost, highly reliable, and user friendly system that is capable of providing real-time weight, gamma, and neutron energy confirmation from each item stored in a SNM vault. CAVIS systems are currently being designed and tested for vault configurations at the Oak Ridge Y-12 Plant*. This paper describes the sensor technologies, the CAVIS prototype system (built at $Y-12$ for highly enriched uranium storage), the technical requirements that must be achieved to assure successful implementation, and descriptions of sensor technologies needed for a plutonium facility.

\section{INTRODUCTION}

With the end of the Cold War, emphases on long-term secure storage for nuclear weapons grade plutonium and uranium have substantially increased. Both the national and international nuclear arms control agencies must continually attempt to devise the best technological and procedural mechanisms for cost-effectively insuring that the world's supplies of these materials are thoroughly safeguarded. The current safeguard systems operating at DOE facilities today include automated security systems and site-specific material accountability systems. The accountability systems generally rely on physical measurements with specialized equipment and intermittent audits performed by highly trained personnel. These systems for SNM accountability are very labor intensive system and highly procedural.

The United States DOE has specific orders and requirements for US facilities associated with the storage and safeguarding of special nuclear materials. The requirements for physical inventories for Category I and II materials vary depending on the level of activity in the material balance area; however, they have historically been bimonthly. In most cases. the custodian facility does not have the resources (people, time, and money) to inventory $100 \%$ of the materials within its possession during one calendar year, let alone within a two month time frame. For these reasons, sophisticated sampling schemes have been devised, where a portion of the total SNM inventory is randomly tested and inventoried bimonthly.

CAVIS was specifically designed to minimize the labor and radiation exposure associated with SNM inventories. When fully implemented, CAVIS will eliminate the need for sophisticated sampling schemes and allow inventory reconciliations to be completed in minutes. CAVIS is an integrated. virtually passive sensor system designed to continuously monitor stored nuclear (radioactive) materials. CAVIS uses fiber optic and solid state sensors to verify item weight, item temperature, gamma ray flux, relative uranium enrichment, neutron flux, item location, and item motion.

,

The system described in this document was developed to monitor weapons grade uranium stored in a large matrix of modular storage vaults (MSV). ${ }^{1}$ These technologies can be adapted to monitor neutron flux (plutonium), temperature, pressure, item identification, ${ }^{2}$ and isotopic enrichment. This flexibility creates a complete, integrated system capable of remotely verifying radioactive material attributes for items stored in a variety of configurations (including both static and dynamic storage environments). These include contaminated wastes, reactor fuel elements, reactor byproducts, or treaty controlled special nuclear materials. The sensor systems in the CAVIS prototype (specifically

* Managed by Martin Marietta Energy Systems, Inc. for the U. S. Department of Energy under contract DE-AC05-840R21400 
designed for the storage of uranium materials) are fiber optic weight sensors, small semiconductor (silicon PIN diodes and photosensors) devices, and fiber optic gamma radiation sensors. These devices are highly reliable and have been specifically designed for monitoring physical attributes associated with enriched uranium. The sensors are connected to a multiplexing device which, along with the specialized computer software, can rapidly poll each storage location and verify each item's weight, temperature, and gamma-ray activity. Any change in these attributes provokes an immediate response to the appropriate alarm system.

With the semiconductor radiation sensors. CAVIS is capable of estimating the relative isotopic enrichment of a specific item. CAVIS was designed with active components outside the storage vault so that items can be continuously inventoried and remotely monitored for material change or diversion without personnel access. The passive sensors produce unalterable physical outputs which can potentially provide independent auditing organizations (such as the Intemational Atomic Energy Agency (IAEA)) with the capabilities they need, including remote data collection using telemetry. The remote monitoring feature serves a dual purpose; it reduces any potential security vulnerability associated with hands-on inspections and protects personnel from radiation exposure.

The system discussed in this repor can protect personnel from radiation exposure, reduce monitoring costs, and provide a quick (100\%) inventory of all items stored in SNM vault. CAVIS meets or exceeds all current DOE requirements for inventorying stored nuclear materials and is potentially adaptable to a variety of radioactive material storage configurations and needs (e.g., waste storage areas, radioactive spill detection, spent nuclear fuel monitoring, emergency inventory verifications, etc...).

\section{THE OAK RIDGE Y-12 PLANT}

One of the Oak Ridge Y-12 Plant's expanding missions in the post cold war era is the long-term storage of SNM. To accommodate this mission, Y-12 is required by the DOE Orders to perform periodic confirmation/verification measurements of its inventory of SNMs. The purpose of these measurements is to provide additional assurance that the SNMs are secure and have not changed since the last inventory. Current confirmatory measurements require entry into the storage vaults (which mandates the need for additional security measures) by several highly trained individuals. The cost.of these tasks in personnel time alone is approximately $\$ 200$ per inventoried item. Because of these and other associated overhead costs, only 2.5 percent of the total SNM vault inventory is verified during each inventory period.

The CAVIS provides a low cost, highly reliable, and virtually passive sensor system that is capable of obtaining near real-time weight and gamma ray signature measurements from all $(100 \%)$ of the stored items. The current (manual) system costs Y-12 approximately $\$ 180 \mathrm{I}$ : annually for only a $2.5 \%$ coverage of confirmatory measurements. This cost is expected to grow as new MSVs are implemented (since these will require near complete disassembly to accommodate manual measurement access). CAVIS provides $100 \%$ continuous confirmation of a vault inventory at an estimated annual operating cost of about $\$ 10 \mathrm{~K}$. Even if no other vaults are built, Y-12 could realize an approximate cost savings of $\$ 170 \mathrm{~K}$ each year and enhance its monitoring capabilities from $2.5 \%$ to $100 \%$ of SNM materials. This would be equivalent to spending $\$ 7.2 \mathrm{M}$ annually to provide $100 \%$ confirmation using the present system. Figure 1 is an illustration of the MSV prototype system that was recently built to demonstrate the CAVIS technologies.

\section{CA VIS SENSOR DESCRIPTIONS}

CAVIS is a completely integrated system that incorporates four types of sensor technologies, a sophisticated monitoring program, specialized electronics for signal discrimination and data analysis, and commercial data handling and processing components (computer and communication electronics). The four sensor technologies are:

\section{A. OPTICAL FIBER-BASED WEIGHT MEASUREMENT SYSTEM}

The CAVIS optical fiber-based weight measurement system can measure the weight from thousands of SNM containers in a storage vault. The measurement system consists of individual fixtures for holding the storage containers, optical-fiber weight sensors integrated into the fixtures, and an electrical interface that connects sensor outputs to a multidrop network and a control computer. The fixtures and interface can be adapted to work in a variety of vault configurations.

There were several design criteria for the operation of the weight sensor system: 1) the sensor system must weigh all containers in the storage vault system, and it must weigh each item at a frequency such that mean time between measurements is much less than the time required to physically remove and replace the material: 2) each sensor must have a measurement uncertainty that is less than or equal to 5percent of container mass; 3 ) the system must be reliable and easy to maintain; 4) the system must be hard to environmental conditions present in the vault (ambient temperature, humidity, and background radiation); 5) the system must be implemented with all signal processing hardware external to vault; and 6) the system must have a false alarm rate of less than one per month and false alarms must be verifiable without access to the vault. 


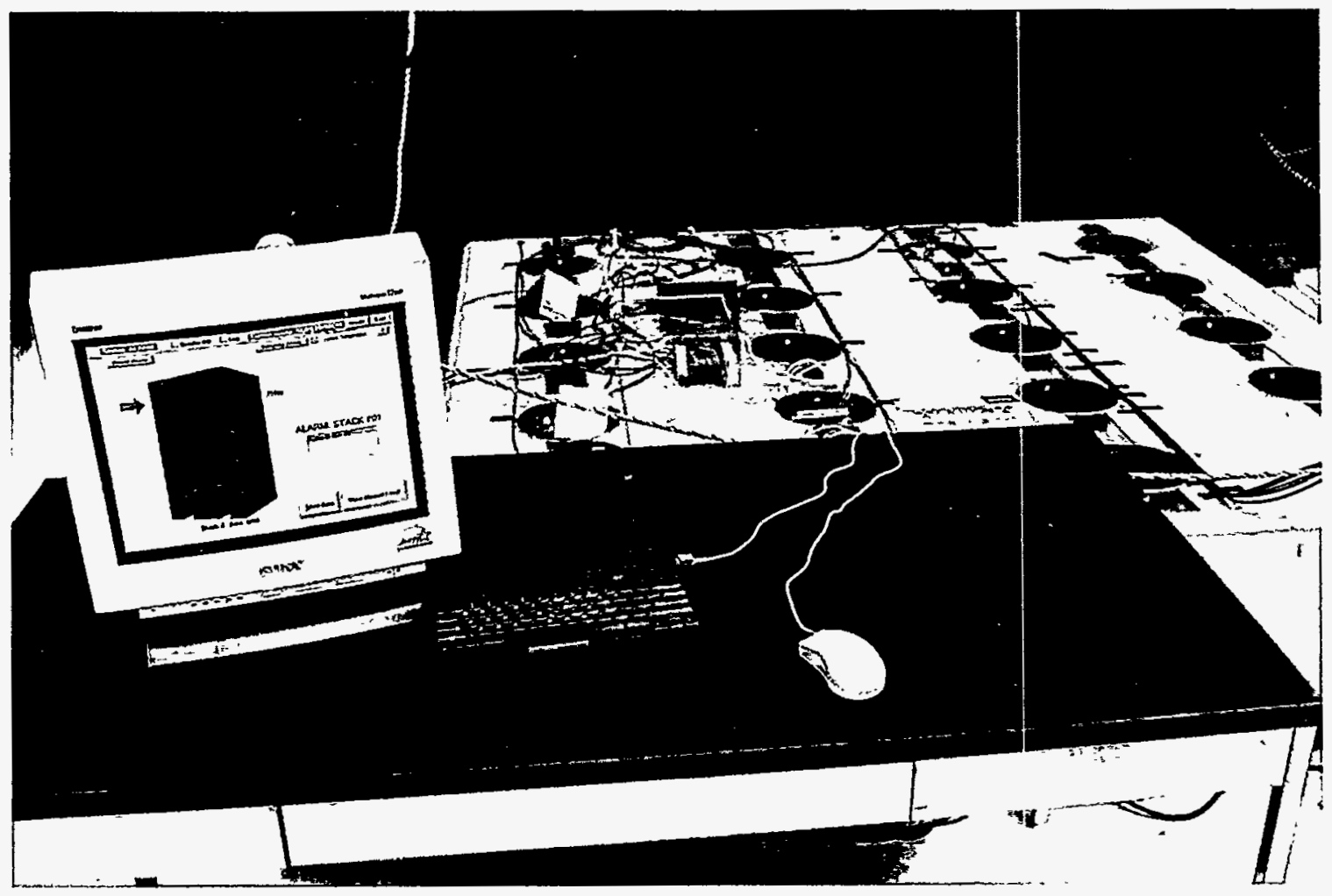

Figure 1: CAVIS Demonstration System Built for a Modular Storage Vault (MSV)

\section{WEIGHT SENSOR DESCRIPTION}

The weight sensor unit uses an intensity-based fiber optic sensor to measure container weight. The optical fiber used in the sensor is fabricated entirely of silicone rubber. The weight sensor is constructed so a SNM container will compress polyurethane load bearing elements that are mechanically coupled to the optical fiber through a series of deformer pins (see Figure 2). The deformer pins produce microbends in the optical fiber, which decrease light transmitted by the fiber in proportion to the degree of microbending. This decreasing intensity of light is transmitted through the fiber and is directly correlated to the weight of the item. Figure 3 is a picture of an assembled weight sensor built for a MSV. The cavity or cut-out in the center of the sensor is to accommodate one of the small radiation sensors described in the succeeding sections..

The components shown in Figure 2 are the polycarbonate top and bottom plates of the fixture, the silicone rubber optical fiber, the polyurethane load bearing elements, the deformer pins, the light emitting diode source, the phototransistor detector, and a semiconductor temperature sensor. The fixture is approximately $19 \mathrm{~cm}$ in diameter and $2.9 \mathrm{~cm}$ thick. The weight sensors are interfaced to the system control computer through sensor concentrators (see Figure 4) and a two-wire multidrop network The sensor concentrator electronics supplies $+5 \mathrm{~V}$ power to the Light Emitting Diode (LED) and phototransistor and does a 12-bit analog to digital conversion of the output voltage from the phototransistor.

The weight sensor is operational within the temperature range 0 to $38 \mathrm{C}$. The sensitivity of the sensor varies slightly over this temperature range, and the best accuracy is obtained when the sensor is calibrated over the range of temperatures to which it will be exposed. The sensor output may not be constant over extended periods, and there is some drift up and down across the baseline signal as well as a long-term migration of the baseline. This drift is due to temperature instabilities in the LED and phototransistor, fluctuations in the voltage supplied to the LED and phototransistor, aging of the LED, phototransistor and silicone rubber optical fiber. Fortunately, all of these instabilities can easily be compensated for with feedback control algorithms in the software.

The effect of low-level gamma radiation $(<200 \mathrm{mr} / \mathrm{h})$ is expected to be minimal on the long-term performance of the weight sensor. The accumulated dose over the design lifetime (about twenty years) will be about $35 \times 10^{3} \mathrm{r}$, and the LED and phototransistor are known to be hard under this exposure. The mechanical properties of silicone elastomers are relatively immune to gamma radiation, but the optical properties are not known. To that end a special test procedure was designed to test the mechanical and optical properties of the silicone rubber optical fiber after accelerated aging tests in a low-level gamma radiation field. 


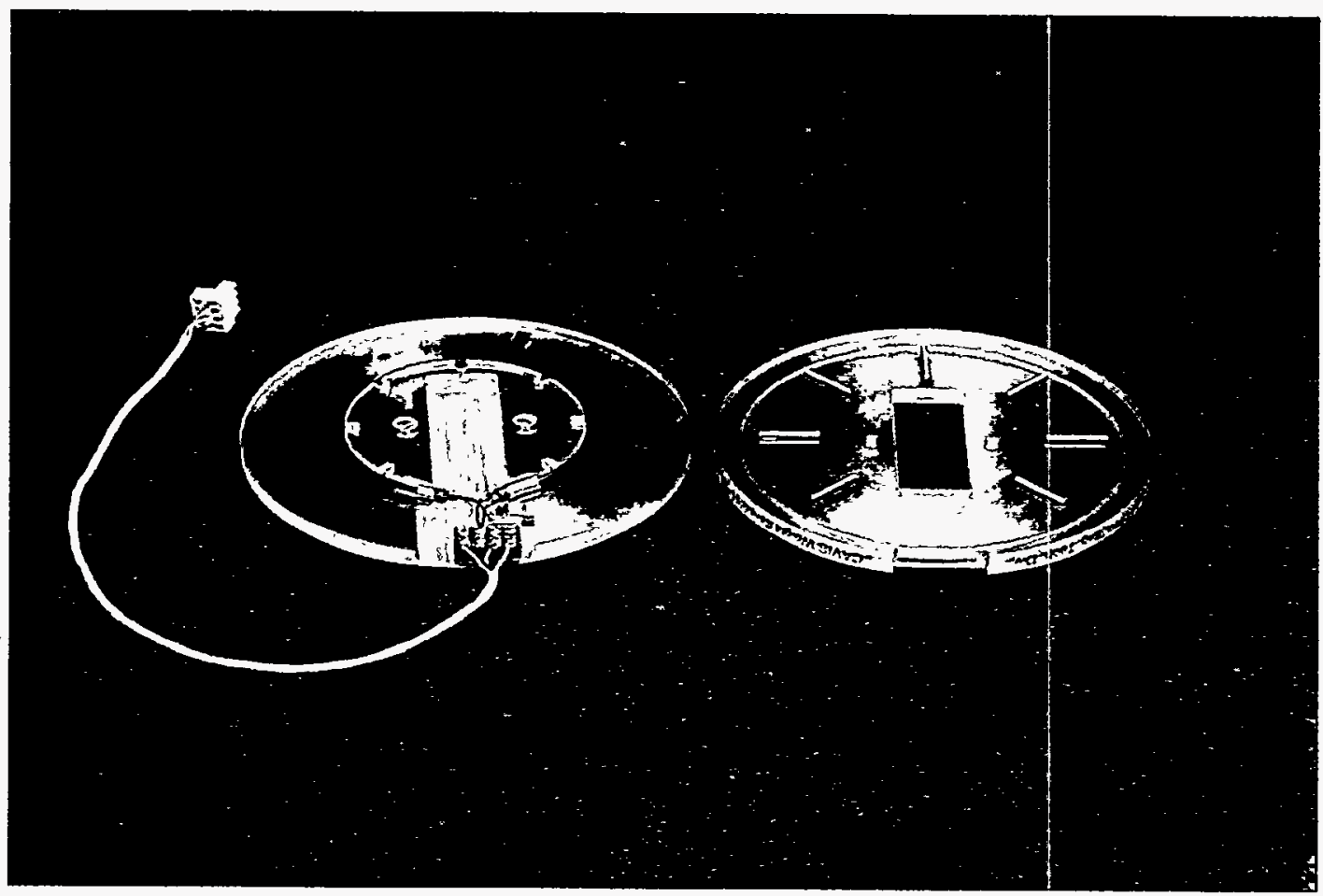

Figure 2: Fiber Optic Weight Sensor for MSV Storage Configuration

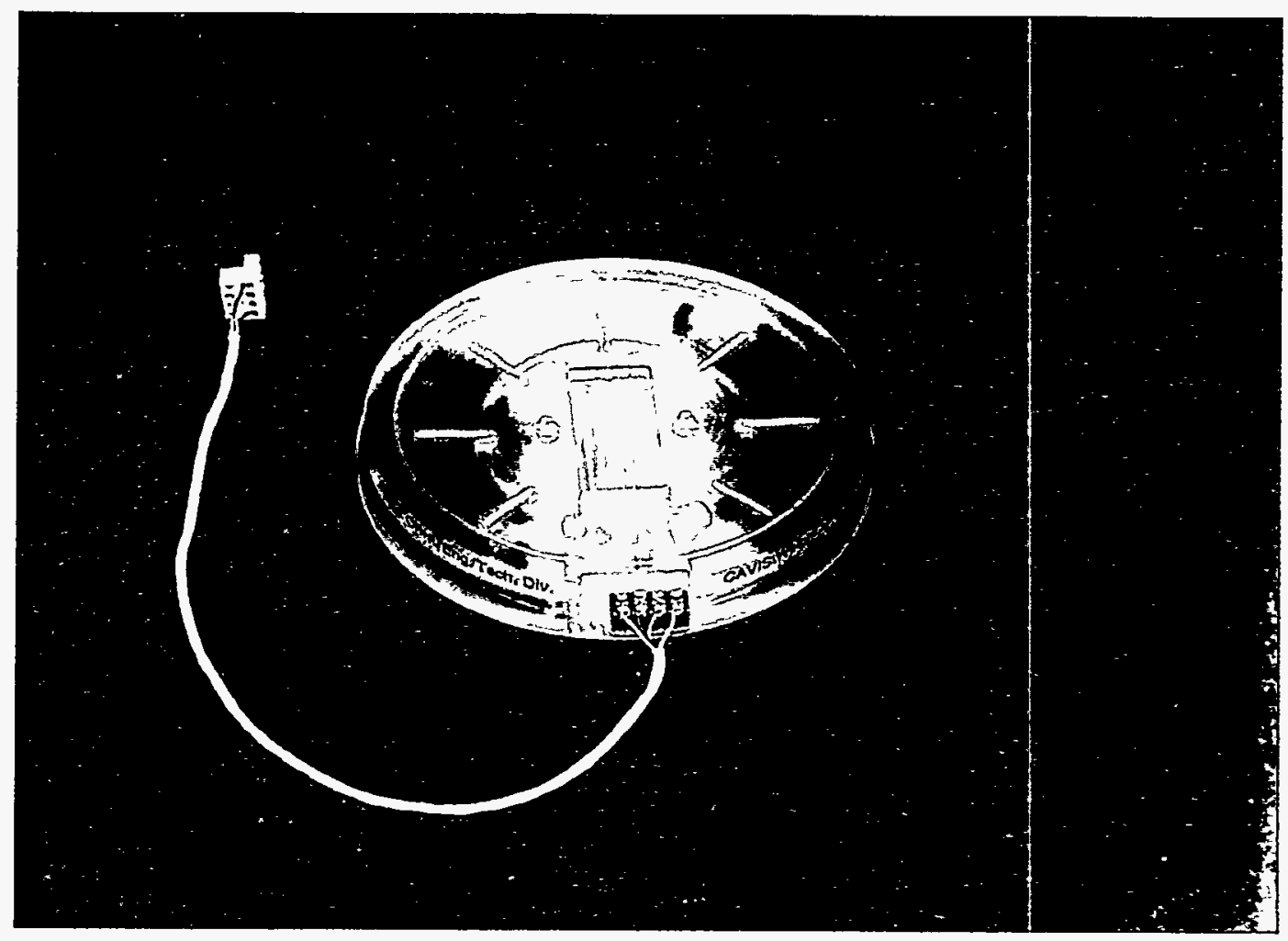

Figure 3: A Fully Assembled Weight Sensor Built for a MSV 


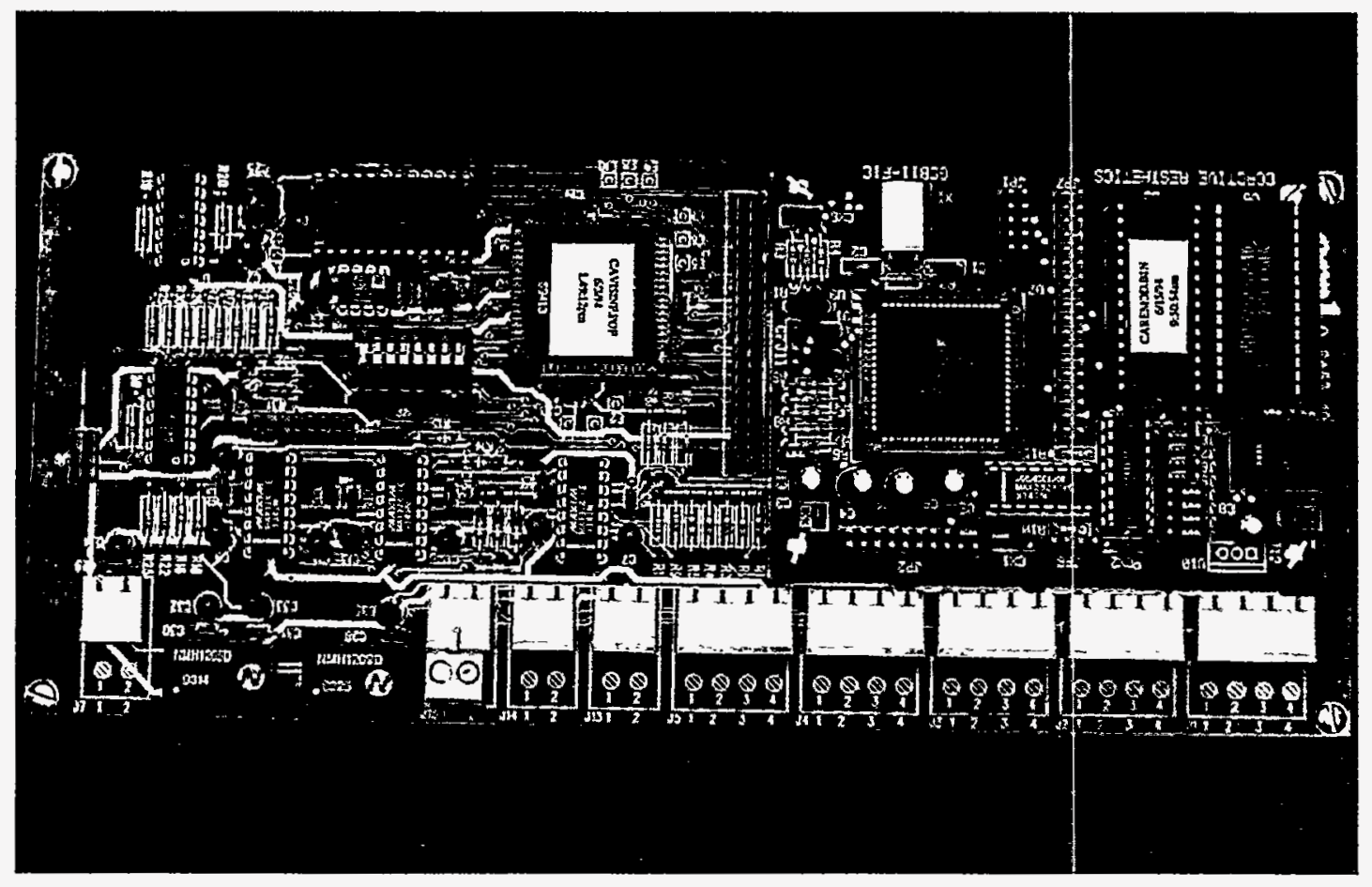

Figure 4: The Sensor Concentrator Board Designed for Connecting Sensor Outputs to the Computer

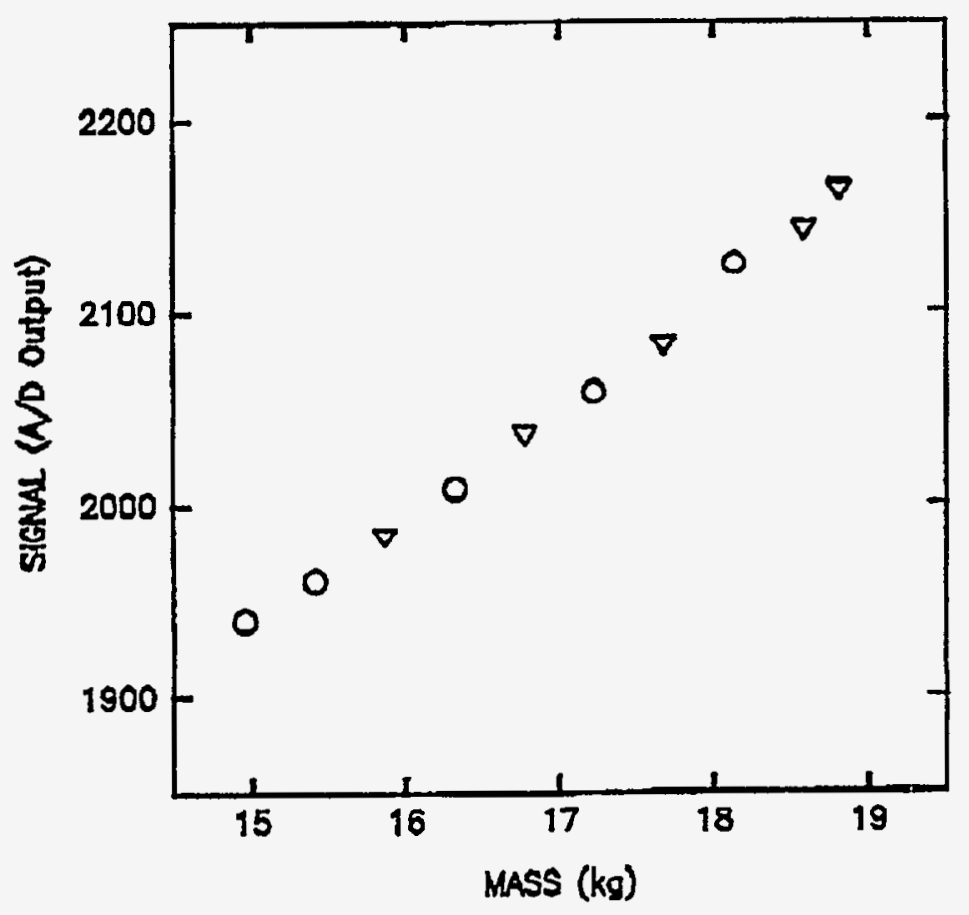

Figure 5: Correlation of Weight Sensor Output Response to Applied Loads: $O$ - Mass Loading and $\Delta$ - Mass Unloading 


\section{WEIGHT SENSOR PERFORMANCE AND COST}

The graph shown in Figure 5 illustrates the response of a typical weight sensor to applied loads. The sensor is designed to operate with loads in the range 15 to $19 \mathrm{~kg}$. The output is very nearly linear in this range. There is some slight amount of hysteresis; however, the maximum measured difference in sensor output signal during loading and unloading cycles is less than 5 percent. The measured accuracy of the weight sensors is 5 percent or better in the range 15 to $19 \mathrm{~kg}$.

The total cost for the weighing 2000 containers is about $\$ 58,500$, or approximately $\$ 29$ per container. This cost is significantly lower than that reported for other weight measurement technologies.

\section{FUTURE DEVELOPMENTS FOR WEIGHT SENSORS}

In the second year of CAVIS weight sensor development (FY 1995) we plan to deploy about 60 weight sensors in a MSV. The sensors will be loaded with containers having masses similar to those expected for real materials. The sensor output data will be logged over a period of six to nine months and it will be analyzed for performance under real operating conditions. Particular attention will be paid to the long-term stability of the sensor output and reproducibility of the sensor calibration curve.

Results are expected soon from accelerated radiation aging tests on the silicone rubber optical fiber. This data will provide a verification of the expected lifetime of the weight sensors in the vault environment.

Plans are also continuing to find ways of reducing the manufacturing costs associated with mass production of the weight sensor. One avenue for cost reduction is to reduce the parts count; this will decrease the hardware and assembly costs. Another avenue for cost savings is to die cast the sensor top and bottom plates; eliminating the machining costs associated with polycarbonate stock. A. zinc alloy is a very attractive material for the die cast parts, from both cost and performance standpoints.

\section{B. FIBER AND SCINTILLATOR TECHNOLOGY (FAST) DETECTORS FOR GAMMA AND NEUTRON FLUX MEASUREMENT}

For long-term storage of SNM, the advantage that Fiber Optic and Scintillator Technology (FAST) detectors hold over more conventional approaches is passive operation. Here, passive operation is defined as the absence of any active components (electronics, power supplies, etc.) within the vault area. The major benefits of a monitoring system incorporating FAST detectors are reducing the frequency and intensity of physical inventories and reducing the needs for safeguard staff to access a storage vault for maintenance. Conservative estimates of cumulative gamma dosages which FAST detectors can withstand before failure would be in the 10 to $100 \mathrm{MRad}$ region ${ }^{3}$. This would translate into reliable operation over 1,000 to 10,000 vault years assuming dose rates of $1 \mathrm{Rad} / \mathrm{Hr}$. Cost estimates for a system incorporating FAST detectors is approximately $\$ 50 /$ item monitored. A SNM monitoring system that incorporates FAST detectors will thus provide cost effective, reliable, remote inventories of material attributes for the safegaurds community.

\section{FAST OVERVIEW}

The FAST detector system for SNM in storage provides a scintillator material (plastic scintillator for gamma radiation or ${ }^{6} \mathrm{LiF}$ and $\mathrm{ZnS}(\mathrm{Ag})$ powders in an epoxy binder for neutrons) for each item to be monitored that converts ionizing particles to photons (light energy). The photons are then coupled into a fiber optic cable using wavelength shifting (WLS) fiber and transmitted to a location outside the vault area. In this configuration. there are no active components inside the SNM storage vault, therefore. the system has no maintenance requirements and the need for human intervention is minimized.

To be a cost-effective solution for inventorying SNM items, however, a method must be implemented to monitor multiple items with a single photodetector. This reduction in hardware and complexity is accomplished by feeding multiple fiber sensors into a 2-D photomultiplier tube (PMT -Hamamatsu Corp.. P/N R2487-01) which has a crossed wire grid anode structure. In this configuration, an array of individual fibers, each of which monitors a discrete item, is butt-coupled to the sensitive area of the tube as an X-Y array. The $X-Y$ wire grid anode of the tube provides the location of an event (ionizing particle from a single SNM item) and the processing circuitry records the number of events per unit time at that location (flux). Assuming 2-mm diameter fibers and given the sensitive area of the PMT of 7 $\mathrm{cm} X 7 \mathrm{~cm}$, an array of $35 \times 35$ fibers can be interfaced to a single tube, thus providing monitoring capability for 1,225 discrete SNM items. The cost of the PMT + processing/interface electronics is $-\$ 10.5 \mathrm{~K}$, which. with the cost of the FAST sensors and computer hardware, brings the per item cost of the system to $<\$ 50$. A system block diagram is shown in Figure 6.

Each of the wire anodes of the PMT is connected to a charge-sensitive pre-amp with conversion gain of 1 volt $/ \mathrm{pC}$ followed by a shaper amplifier with a voltage gain of 225 and a shaping time constant of 300 nanosec. The output of each shaper amplifier is connected to a quad discriminator/Emitter Coupled Logic (ECL) line driver integrated circuit. Further reduction in the cost of the system and increase in the system reliability was obtained by implementing the analog circuitry using Application Specific Integrated Circuit (ASIC) technology. The discriminators are connected to a common discriminator voltage reference, typically set at 0.5 volts. Redundant fibers run from each item sensor are placed in contact with the face of a single Hamamatsu R1924 PMT. The two 


\section{FIBER-OPTIC and SCINTILLATOR TECHNOLOGY (FAST) DETECTOR SYSTEM for SNM STORAGE}

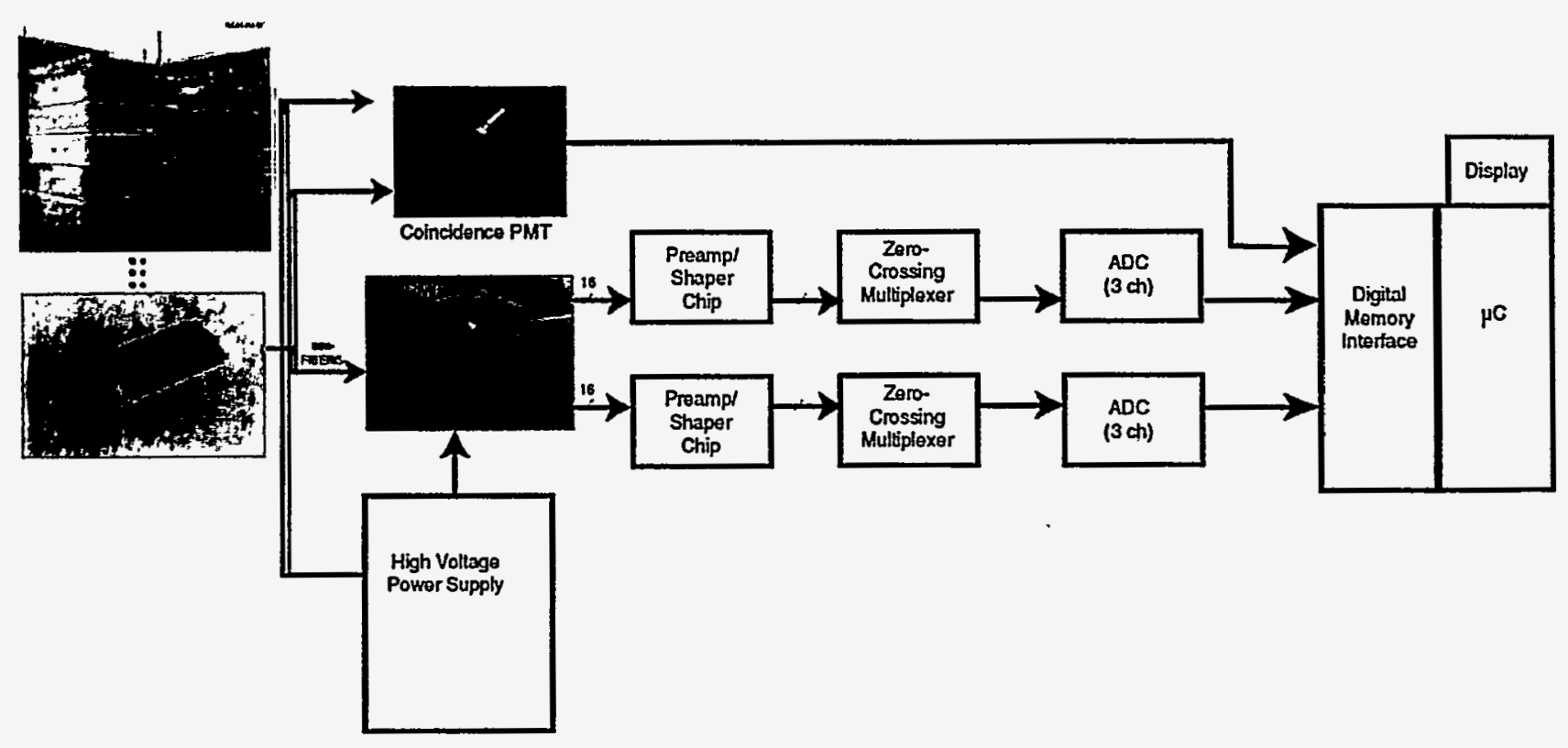

Figure 6: Schematic Block Diagram of FAST System

PMTs (the 2-D R2487 and the single R 1924) are operated in the coincidence mode to eliminate tube noise and direct interaction of the PMTs with background gamma rays. The anode of the R1924 is connected to an identical chargesensitive pre-amp, shaper amplifier, and discriminator as the R2487. The digital output of the discriminators are connected to a digital logic board that collects and stores only those counts from the cross-wire tube which are in coincidence with pulses from the R 1924 . The data from the logic board is transferred to a PC-compatible computer by a Direct Memory Access (DMA) interface on the board.

Scintillator technology for monitoring flux is not new 4 . Likewise using fiber optics and specifically WLS fiber to couple to scintillator material for remote monitoring has been developed in the past for programs such as the Super Collider Superconductor (SSC) 5 . Finally, using multi-anode $X-Y$ grid PMTs or 2-D microchannel plates (MCPs) to obtain positional and flux information for applications such as $\mathrm{x}$-ray imagers or detector components for high energy physics experiments is not new 6 . What is novel about our concept is bringing together these technologies as a system to provide cost-effective passive monitoring for SNM storage facilities.

\section{TEST RESULTS}

There are several fiber optic sensor configurations we investigated for monitoring gamma radiation. The first configuration consisted of a grooved, Bicron BC- 400 plastic scintillating disk, an embedded WLS fiber stub, and a clear section of plastic fiber optic cable which interfaces to the 2Dimensional (2-D) PMT. The SNM item sits on top of the scintillating disk and the resulting emission of blue light pulses from scintillator events is absorbed and remitted as green light pulses in the WLS fiber and transmitted through the clear fiber to the PMT. Due to the efficiency of light transmission in the clear fiber, the 2-D PMT and associated electronics can be located remotely, 10's of meters away. A second configuration consists of segments of scintillating fiber (as opposed to a scintillating disk) and clear plastic fiber cable which again is coupled to the 2-D PMT. The advantage of this configuration is that the scintillating fiber can be coiled around the SNM item providing greater flexibility in implementing the monitor in existing vaults. The third configuration is a grooved rectangular bar of scintillator material, an embedded WLS fiber stub, and a clear section of plastic fiber optic cablewhich interfaces to the 2-D PMT. This configuration also provides greater flexibility for existing vaults where the bar can be inserted 


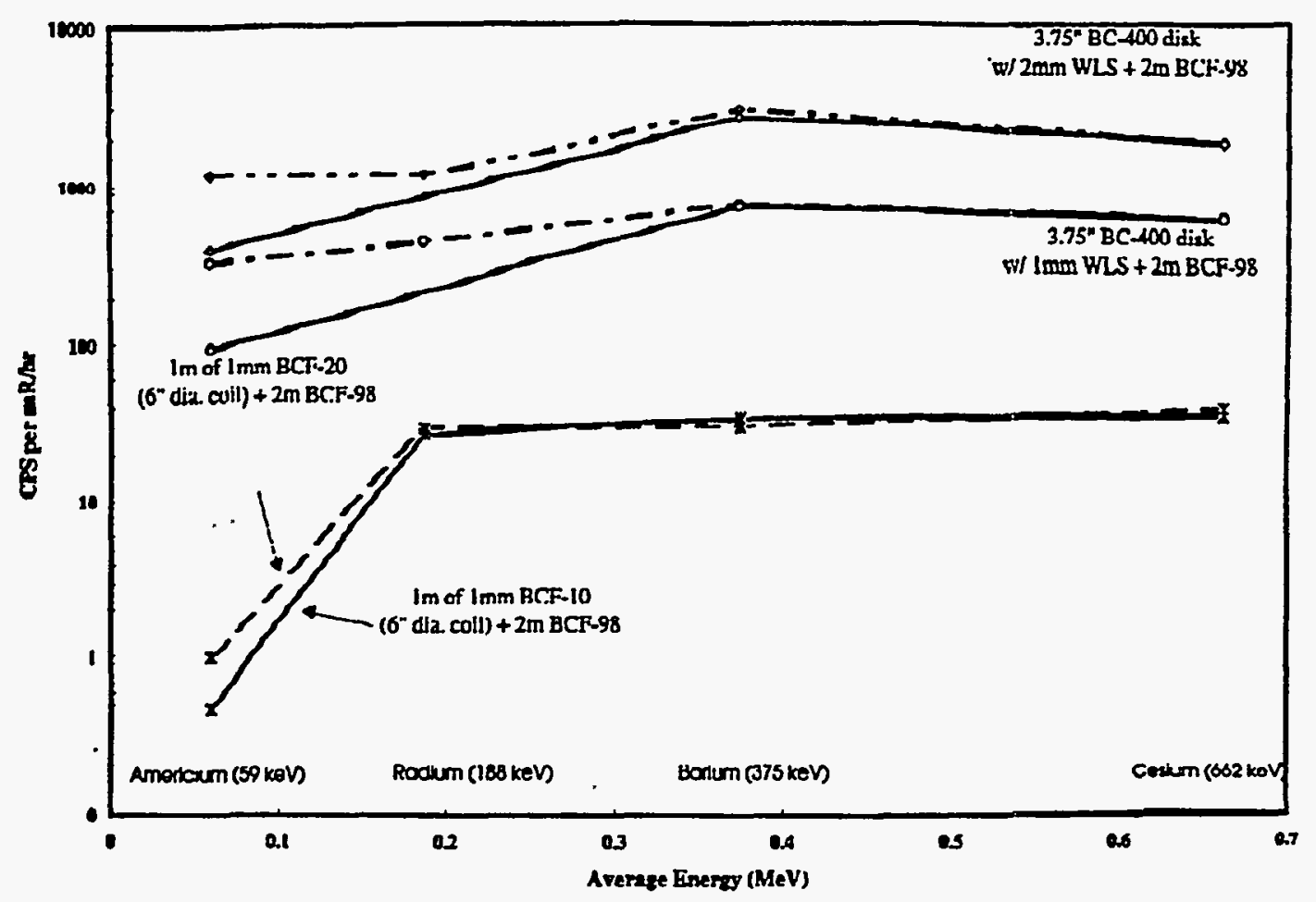

Figure 7: Scintillation Counts per Second (CPS) per mR/hr versus Average Energy

next to the SNM item. Figure 7 shows the resulting counts per $\mathrm{mR} / \mathrm{hr}$ for various energy gamma sources (Americium, Radium, Barium, and Cesium) using different gammasensitive sensor configurations.

For the detection of neutrons, a sensor consisting of a $6 \mathrm{LiF}$ and $\mathrm{ZnS}(\mathrm{Ag})$ powders in an epoxy binder and coupled to $\mathrm{a}$ wavelength shifting optical fiber was constructed. Like the gamma scintillator sensors mentioned above, the scintillator light is coupled to a PMT via a WLS fiber butt-coupled to a clear fiber. Two experiments were performed to determine the viability of the detector design: (1) a measurement of the neutron detection efficiency of several ${ }^{6} \mathrm{LiF}$ and $\mathrm{ZnS}(\mathrm{Ag})$ samples on a $56.9 \mathrm{meV}$ neutron beam on the HB-1B beam line at the High Flux Isotope Reactor (HFIR) at Oak Ridge. and (2) a measurement of the gamma-ray sensitivity of the samples using a ${ }^{137} \mathrm{Cs}$ gamma emitter and a ${ }^{90} \mathrm{Sr}$ bremsstrahlung source to simulate the measured gamma background of HFIR. Five samples were prepared by mixing ${ }^{6} \mathrm{LiF}$ and $\mathrm{ZnS}(\mathrm{Ag})$ powders with eccobond \#27 clear epoxy in a $2.54 \mathrm{~cm}$ diameter mold. The mass ratio of ${ }^{6} \mathrm{LiF}: \mathrm{ZnS}(\mathrm{Ag})$ was held to $1: 3$. The samples are made by mixing the powders with uncured epoxy and pouring the mix into a glass mold. The powder then settles to the bottom of the mold before the binder cures. After curing, the clear epoxy above the settled powder mix is removed by machining. The resulting samples are of different thicknesses because of the varying quantity of ${ }^{6} \mathrm{LiF}$ and $\mathrm{ZnS}(\mathrm{Ag})$ powders. The results of the tests on the samples are shown in Figure 8. The neutron conversion efficiency is plotted versus the mass density $\left(\mathrm{mg} / \mathrm{cm}^{2}\right)$ of ${ }^{6} \mathrm{LiF}$. The open squares represent the measurements for the $56.91 \mathrm{meV}$ beam energy from the Bragg crystal. The sample containing a mass density of $6_{\mathrm{LiF}}$ of $40 \mathrm{mg} / \mathrm{cm}^{2}$ demonstrated the highest efficiency of approximately $60 \%$. The pulse height distribution for all five samples indicated that a lower threshold (therefore, higher conversion efficiency) can be used without adversely affecting the background due to tube noise and/or gamma rays.

In order to assess the gamma ray rejection of the scintillator. a Nal(T1) crystal $(2.54 \mathrm{~cm} \times 2.54 \mathrm{~cm} \times 2.54 \mathrm{~cm})$ mated to an R1924 tube is mounted immediately behind a sample holder. In this manner, the gamma radiation passing directly through the scintillator/fiber sample can be directly measured at the same time events are recorded by the neutron scintillator/fiber system. The ${ }^{137} \mathrm{Cs}$ gamma emitter and ${ }^{90} \mathrm{Sr}$ sources were then placed in direct contact with 


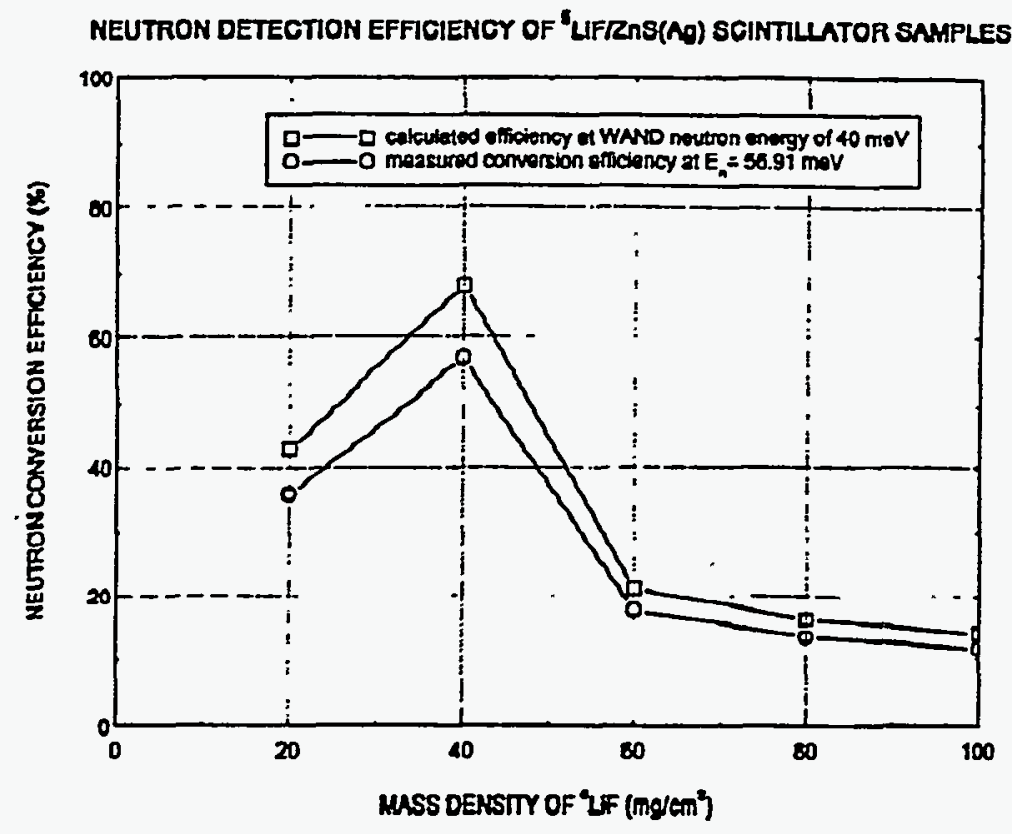

Figure 8: Neutron Detection Efficiency of ${ }^{6} \mathrm{LiF} / \mathrm{ZnS}(\mathrm{Ag})$ Scintillator Samples

the sample scintillator/fibers. The resulting gamma ray rejection of the neutron detector varied from $1 / 600,000$ to $1 / 1,200,000$ depending on the range of pulse height channels used for the calculations.

Two systems have been described for passively monitoring SNM material using fiber optic sensors. One system uses plastic scintillators to sense gamma radiation and the second uses ${ }^{6} \mathrm{LiF}$ and $\mathrm{ZnS}(\mathrm{Ag})$ powders to measure thermal neutrons. Both sensors were configured into prototypes and tested. Test results indicate that the systems will provide the capability of monitoring both plutonium (with a moderator present) and uranium, remotely (10's of meters away) at a cost of $<\$ 50 / i t e m$.

\section{SILICON PIN DIODE WITH DISCRIMINATING ELECTRONICS}

This development provides a radiation detection sensor system (about \$15/channel) which has a useful dynamic range from background to $400 \mathrm{R} / \mathrm{hr}$, with a sensitivity selected for the gamma energies above $60 \mathrm{keV}$. A discriminator circuit eliminates noise that has spikes equivalent to the amplitude of a $60 \mathrm{keV}$ gamma pulse along with all lower amplitude noise. The sensor system uses low cost, high quality, off-the-shelf microchip technology for the amplifier, sensing, and discriminator circuits.

The main elements within the sensor unit are a silicon photo-detector, a low noise pre-amplifier, and a pulseshaping amplifier. The photon detector is reverse biased by the same low voltage power supply that supplies power to the rest of the system. Charge pulses resulting from photon interactions in the silicon detector are produced at an approximate rate of $500 \mathrm{cps} / \mathrm{R} / \mathrm{hr}$. Filters in the pulse shaping amplifier are designed to provide an impulse response having a pulse width of 20 to 50 microseconds. Figure 9 shows this sensor along with the external electronics used for energy discrimination.

\section{DETERMINING RELATIVE ENRICHMENTS OF U235 FROM STORED ITEMS}

The determination of the relative uranium enrichment level, using an inexpensive silicon pin diode, is accomplished by taking advantage of the difference between the gamma energy activity of U235 versus U238. Pulse height discrimination is used to eliminate much of the unwanted noise and low energy pulses (by using an Americium 241 source to set the lower level discriminator). 


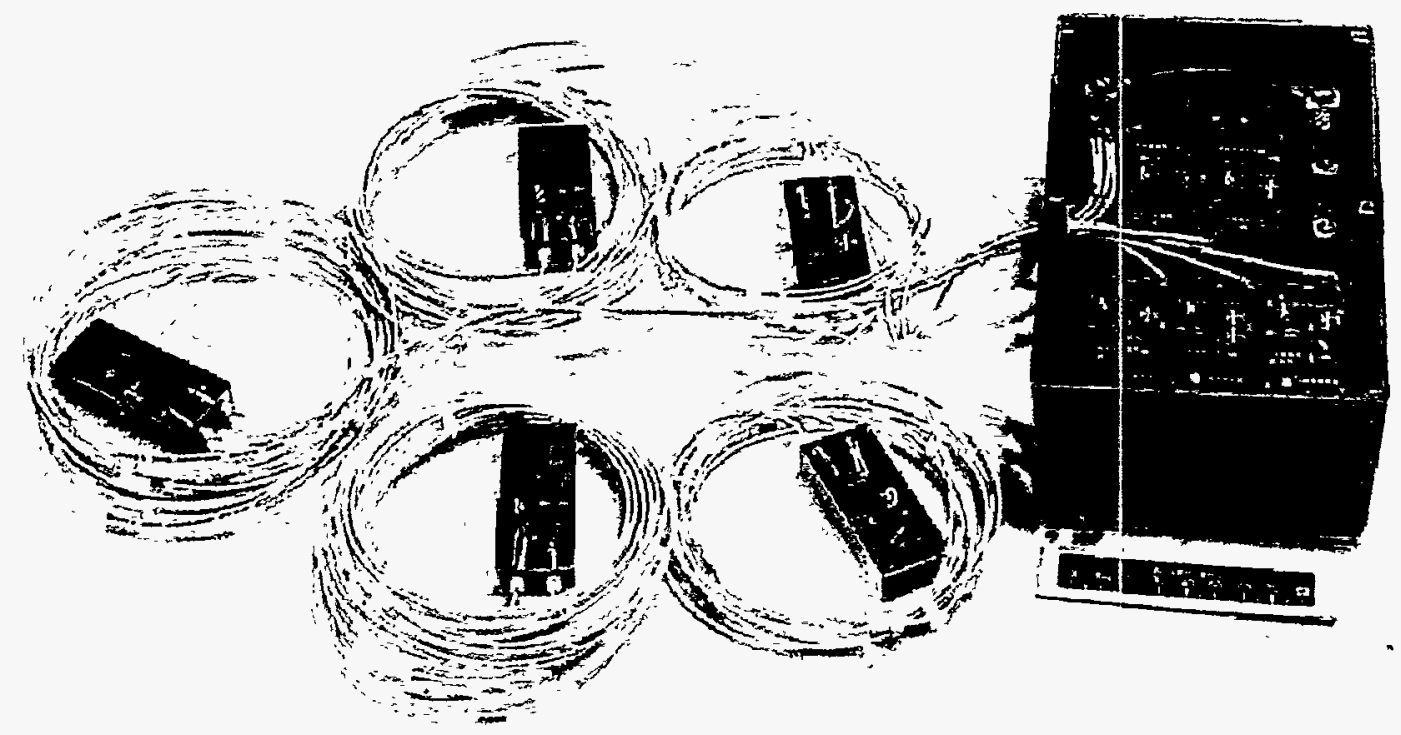

Figure 9: 5-Channel Silicon Pin Diode with Energy discrimination

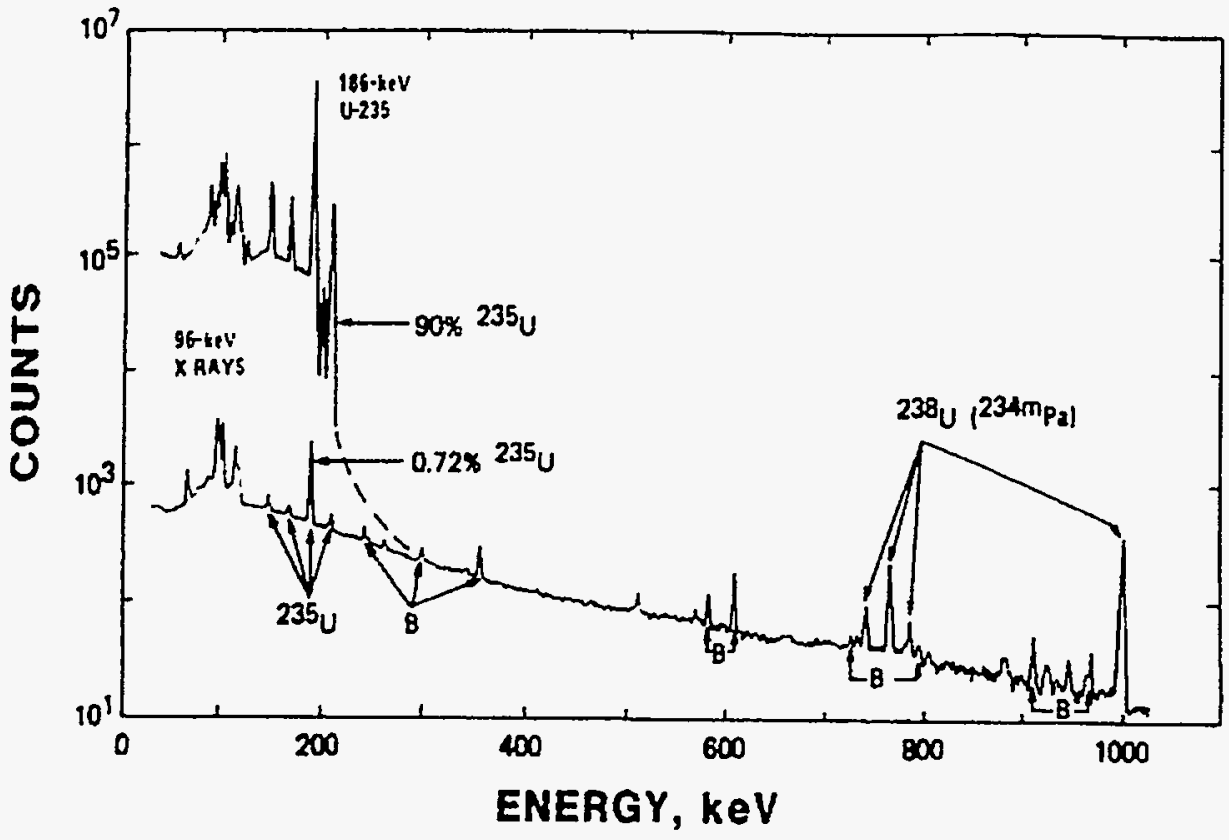

Figure 10: Gamma-ray spectra for natural (0.7\% U235) and 90\% (U235) enriched uranium. The peaks labeled U238 (234mPa) are from the decay of $234 \mathrm{mPa}$. Background peaks are labeled $\mathrm{B}$. Note the increase in the Compton radiation associated with the U235 enrichments. 
The energy band of interest is from the calibrated Am-241 peak to the highest energy from the Compton interaction pulses generated in silicon. The cross section efficiency of silicon radiation detectors is negligible for gamma photoelectron peaks above $100 \mathrm{keV}$. Therefore, only Compton pulses are counted and the Compton pulses below $60 \mathrm{keV}$ are rejected. This sensitivity band is ideal for uranium enrichment measurements.

The spectra illustrated in Figure 10, depicts the increase in U235 enrichments measured with a $\mathrm{Ge}(\mathrm{Li})$ detector. The energy range from $60 \mathrm{keV}$ to $210 \mathrm{keV}$ is the energy range affected by a change in enrichment. The count rate (due to Compton scattering) increases by a factor of 100 in the region associated with silicon, as the enrichment changes from $0.7 \%$ to $93 \%$. The silicon PIN photodiode will not be useful at quantifying low enrichments because of poor counting statistics. However, the count rate will be adequate for measuring relative enrichments above 20 percent.

To calibrate a system to measure relative enrichments. the size, homogeneity. material, attenuation factors, spacing, and detector orientation will have to be the same for each item measured. The count rate versus enrichment will be measured and the $y=m x+b$ line will be stored in the computer for comparison data with other items with enrichments in the range of $20 \%$ to $93 \%$.

\section{SCINTILLATOR - PHOTOSENSOR GAMMA SENSING TECHNOLOGY}

A series of small (1/2-in. dia by $11 / 2$-in. long), inexpensive (about $\$ 15$ each component cost) and durable gamma ray sensors have been developed to provide an effective technique for monitoring the security of SNM in long-term storage. The components for these sensors are virtually passive and the operation is analogous to a thermocouple (except they detect gamma energy instead of temperature).

The sensors consist of silicon photodiodes coupled to small (3/16-in. dia by 1/4-in.) CsI(Tl) scintillator crystals, surrounded by a diffuse white coating to deliver the maximum possible light from the scintillator to the photodiode. They are completely passive in the sense that no power supply is required to energize or bias them. The CsI(TI) crystal is used because of its high density which accommodates the absorption of gamma rays and provides an excellent spectral match of emitted light to the spectral sensitivity of the photodiodes. A LED is mounted on the crystal at the end opposite to the photodiode to allow routine automatic computer controlled testing of sensitivity and time response for each sensor and associated electronic channel. The assembly is potted in electronic-grade RTV (epoxy) compound for shock protection, and enclosed in a light-tight aluminum or brass cylinder that provides the appropriate cable exits. A Complimentary Metal Oxide Semiconductor (CMOS) operational transimpedance amplifier converts the photodetector signal current to a voltage which is monitored by the central control computer.
A change in this output represents a change in the gamma energy associated with a stored item; a condition that would trigger an alarm.

The small size, simplicity. and low cost of these sensors makes possible deployment of one sensor per storage container. in flexible strings like Christmas tree lights, or in strings enclosed in rigid probes designed for specific vault applications. The flexible string arrangement is particularly adaptable for retrofitting to existing storage arrangements and for use with the new MSVs. Figure 11 shows the final package and the schematic design of this sensor.

The computer initiates an alarm immediately if any item is removed from its designated location. The detectors are mechanically very rugged with the attendant capability to withstand almost any credible seismic event. Lifetime of the sensors is expected to be comparable to projected facility lifetimes, with little or no maintenance required. Because of their small size and low power consumption, it is particularly easy to protect them from hostile environments.

As part of a collaborative effort. with engineers at Sandia National Laboratory, this sensor was integrated into a prototype of the Authenticated In-process Monitoring System (AIMS) (see Figure 12). This system is a wireless monitoring device that can be attached to individual or stacks of items stored in environments where hard-wire cabling is not feasible.

\section{CAVIS SOFTWÄRE OVERVIEW}

The current version of CAVIS software, was designed to instrument a section of a MSV. A single MSV consists of a capped "Stack" of concrete "Slabs", each containing 20 hollow cylindrical "Cells". Each cell is a storage location for a unit of stored material and is instrumented with a weight sensor, a temperature sensor, and a gamma sensor. A data acquisition and control system continuously monitors the state of all sensors. The software allows system configuration, sensor calibration, and operation control from an easy-to-use interactive graphical user interface. The software was developed to run on a standard IBM compatible personal computer.

In addition to demonstrating an automated inventory system, this version of CAVIS accommodates all three (of the previously described) gamma sensors in order to evaluate their suitability for various material and storage vault scenarios.

\section{A. DATA ACQUISITION AND CONTROL HARDWARE OVERVIEW}

The system hardware consists of a personal computer, a Module Concentrator, and the sensors. The Module Concentrator (see Figure 5) is a custom electronic device with an embedded microprocessor and data acquisition hardware which collects data from five independent weight sensors, five temperature sensors, five each of two different 


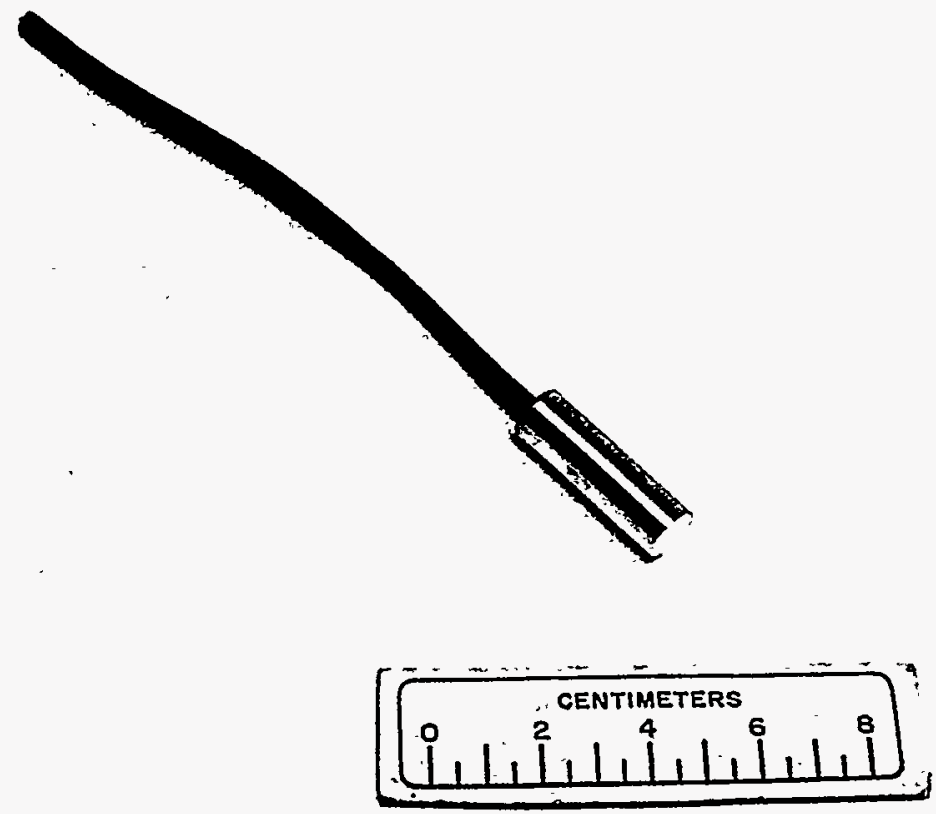

\section{Typical Individual Sensor for 10-Unit Probe}

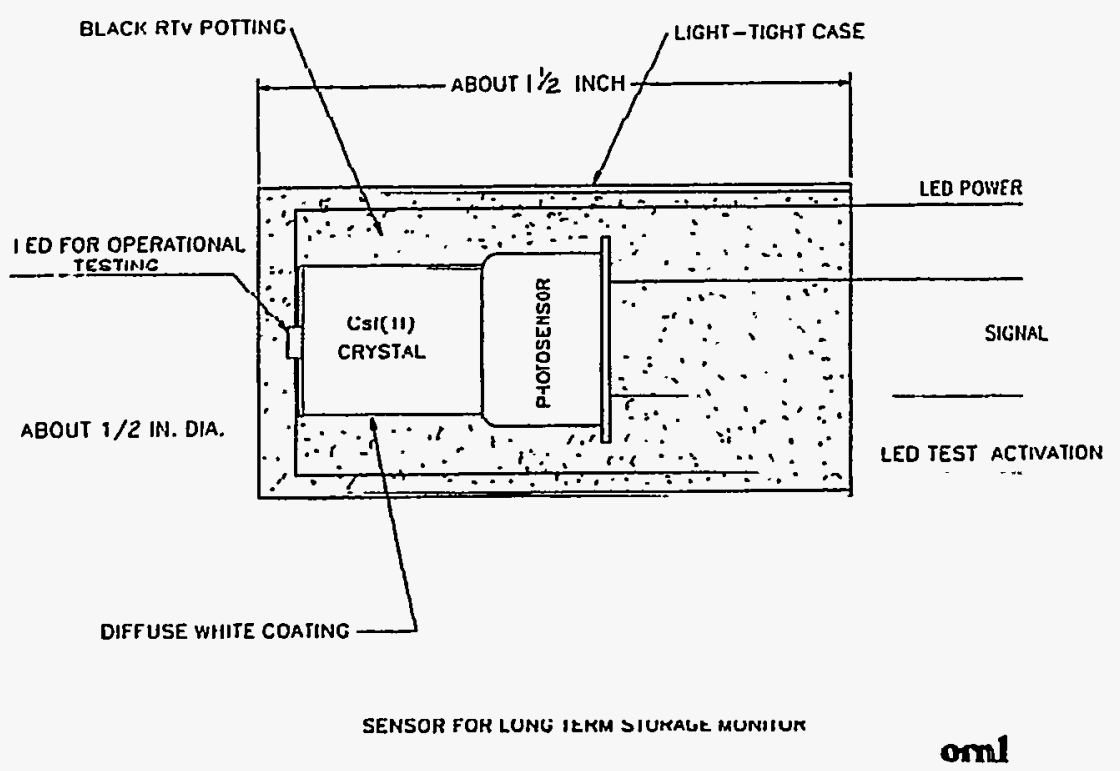

Figure 11: Radiation Sensor and Schematic 


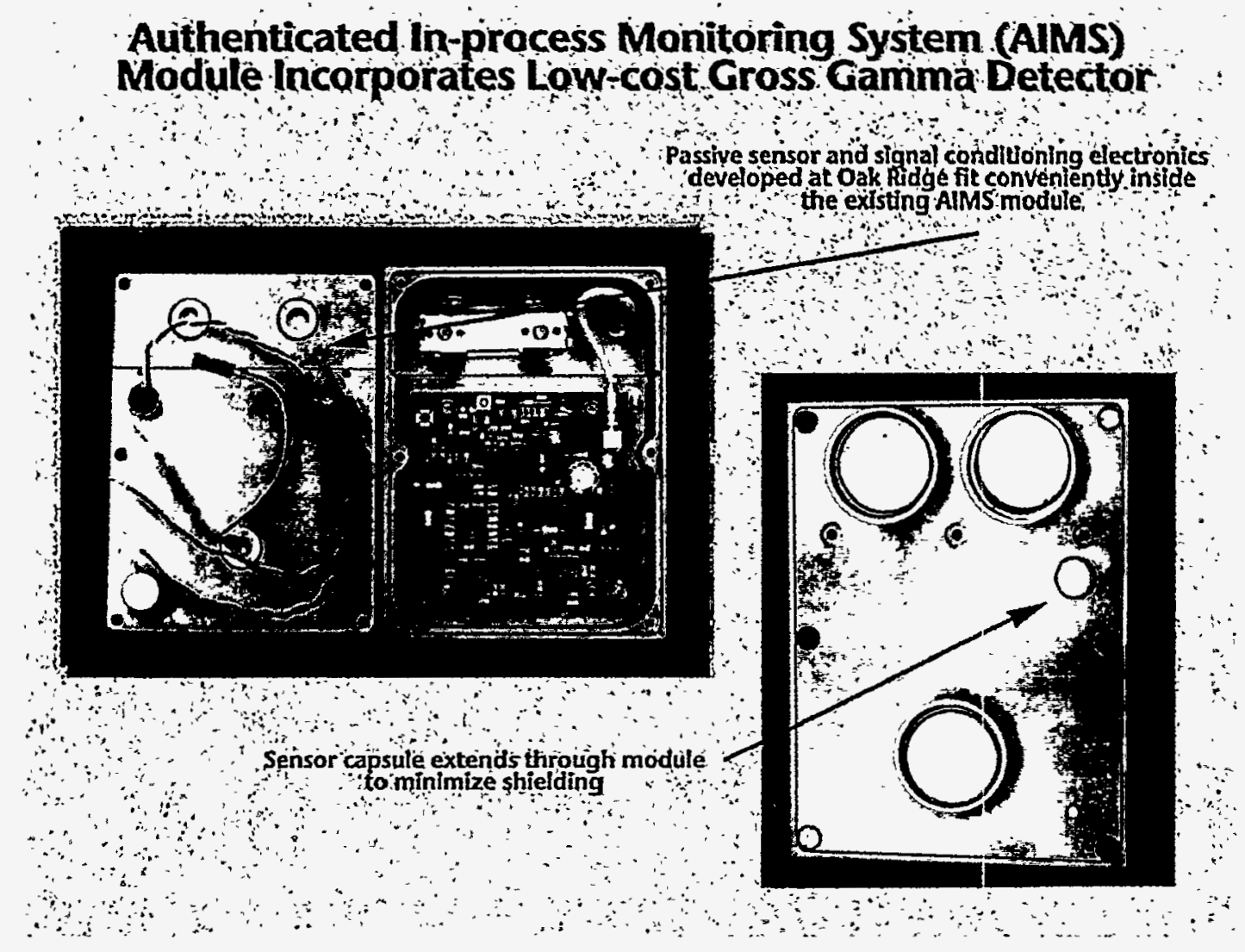

Figure 12: Oak Ridge Radiation Sensor Integrated into Sandia's AIMS Module

types of gamma sensors. The computer is connected to the Module Concentrator by a simple RS-232 serial link.

\section{B. SOFTWARE OVERVIEW}

The software provides a means to control the entire system to demonstrate the effectiveness of CAVIS. It also allows researchers to experiment with various sensor configurations, calibrate sensors, evaluate sensor performance, and perform on-going sensor development. Finally, it demonstrates the potential of several features which may be useful in a final, on-line system, including password protection, interactive configuration, alarm handling, and real-time data display.

To complement the normal operating mode, the software has a Simulation Mode which enables it to run without being connected to the data acquisition hardware.

(Note: The software was developed on a standard IBM compatible computer using Microsoft VB for Windows. This particular development system permits quick prototyping as well as complex algorithm development. In addition to providing a layer of computer hardware device independence, MS Windows allowed the CAVIS software development to result in a friendly, interactive, graphical user interface.)

\section{SOFTWARE OPERATION}

Start the CAVIS software by double-clicking the CAVIS icon from the MS-Windows program manager. As the software loads, it automatically restores the previous state of the system, including the configuration of the sensor arrays. Note that before starting the program, various operating parameters, such as the data sample rate, can be changed by editing the initialization file, CAVIS.INI, located in the Windows directory.

There are three primary screens, the Area, Stack, and Slab screens. All three screens share a control bar at the top which controls sensor monitoring, data logging, and password protection. The "Monitor On" checkbox activates sensor monitoring. The "Log" checkbox enables data logging. To switch between Supervisor Mode and Protected Mode, click on the Mode button.

The initial screen is the Area screen, representing an aerial view of the storage area, with each numbered location corresponding to a single MSV stack. Active stacks are 
distinguished by blue numbers. Click on a stack to display the Stack screen.

The Stack screen shows individual slabs in a side view of the selected stack. An active slab has an identification number displayed to the right. The "Show Area" button will return to the Area screen. Click on a slab to display the Slab screen.

The Slab screen displays the storage cells in the selected slab. The left side of the screen represents a view of all 20 cells in the slab. Each cell is color-coded with the type of sensors it contains, as shown in the key at the bottom of the screen. Click on a cell to select it and display its configuration and contents. The selected cell is outlined in blue for identification. The right side of the screen displays data associated with the selected cell.

The ability to change the configuration is protected by password and can only be changed when the software is in the Supervisor Mode. In the Protected Mode, the user may display but not change the data associated with any storage cell.

When the system is in the Supervisor Mode, the configuration of a cell can be changed. For example, to add or remove a weight sensor, click on the "Weight" check box. The white text boxes, such as the "Date" and slab ID, are changed by selecting the box and typing to edit the data. Click on the "Calibrate" button to define the Module ID, channel number, calibration coefficients, and alarm levels associated with each sensor in the cell.

To start the sensor monitoring, check the "Monitor On" box. The status displayed in the top left comer of the screen will change from "Status: IDLE" to "Status: MONITORING". If the "Log" box is checked, data will be logged to files on the computer's hard disk drive.

When sensor monitoring is active, the latest values from each sensor are displayed under the "current" heading. To display a plot of a sensor's data, click on the "Plot" button. The last ten data points plotted in the graph, which is updated each time the sensor is queried.

To exit the program. click on the "Exit" button from the Supervisor Mode. The "Exit" button is disabled in the Protected Mode to protect against accidental disruption of a monitoring test run.

Note that when the "Enable Simulation" box is checked, the program enters a Simulation Mode. In this mode, the software runs independently of the data acquisition hardware and provides random, simulated data to test the system. In addition, a "Simulate Alarm" button is displayed. Click on the "Simulate Alarm" button to demonstrate the Alarm handling features of the software.

\section{SENSOR CONFIGURATION AND CALIBRATION}

A given storage cell can be fitted with a variety of sensors. Each sensor is connected to the system through a selected channel on one of several Module Concentrators, each identified by a unique ID number. To provide for the maximum flexibility in configuring the physical layout of the sensor array, the software maintains two primary data structures. The first, from the perspective of the Module Concentrator, stores all data specific to a particular sensor including baseline value, calibration coefficients, alarm levels, and its physical location in the storage area. The second, from the perspective of the physical storage cell, maintains information on the types and states of the various sensors and their digital connections through the data acquisition hardware. This scheme is complicated somewhat by the requirement to provide for three types of gamma sensors.

The Configuration sub-system provides an interactive means to associate a storage cell with a specific configuration of sensors. The instrumented state of each cell can be described to the system by means of controls within the Slab screen. For example, to associate a particular weight sensor with a given cell, the "Weight" check box is activated for the selected cell.

The "Calibrate" button accesses a Definition and Calibration screen where the Module ID and channel number of the sensor are selected. Calibration coefficients can be entered which will cause a linear calibration function to be applied to each raw data point as sensors are monitored. For a gamma sensor, the type, 1, 2, or 3 must be specified. For a weight and gamma sensor, a "Sample" button will read the current value from a sensor, store it as the base value, and calculate warning and alarm threshold values based on preset percentage constants. These levels can be manually edited as desired. A "Test" button at the bottom right of the screen will read and display the current data from each active sensor in the cell. The controls at the top of the Definition and Calibration screen allow any cell in the system to be accessed without exiting to the main program.

In addition to specifying the sensor configuration, the status of each cell can be specified, including its contents and associated data such as inventory numbers, storage date and description. Sensors on cells that are marked as Empty or Disabled will not be monitored. When the program is exited, all configuration information is saved in a pair of files. CAVDESC.DAT and CAVMDAT.DAT. One additional associated file, CAVMODS.DAT, contains a list of ID's of modules connected to the system.

\section{DATA LOGGING}

Data from any or all sensors may be logged to data files. The sensor configuration on the Definition and Calibration screen has a "Log" box for each sensor. When checked, and when data logging is enabled by checking the "Log" box in the control bar in the main program, an entry will be written 
to a log file every time a sensor is queried. The log files are named MxxxSSc.LOG, where "xxx" is the module ID number, SS is sensor type, and " $c$ " is the channel number. The sensor types are "WT" for weight, "TM" for temperature, "GS" for gamma type 1, or "GU" for gamma types 2 and 3 . Each log entry consists of the raw data value, the date and the time. A data file can be loaded into external software, such as a spreadsheet or a statistical package, for data analysis. In addition, a system file, CAVSTATE.LOG, records the date and time that data logging is activated or deactivated.

\section{ALARM DETECTION}

For this demonstration version of the CAVIS software, alarm handling is provided by comparing each calibrated data value from each sensor against thresholds defined on the Definition and Calibration screen. If a threshold is exceeded, a warning or alarm event is recorded. From the Area screen, the stack containing the alarm is highlighted in red and the time of the first occurrence of an alarm in that stack is listed to the right of the screen. The alarmed Stack view is accessed either by clicking on the stack or the "Show Alarmed Stack" button.

From the Stack screen, the alarmed slab is indicated with a red arrow and the alarm event recorded in alarm list box on the right side of the screen. The alarmed Slab view is accessed either by clicking on the slab or the "Show Alarmed Level" button. From the Slab screen, the alarmed cell is indicated in red, along with an event type indicator next to the alarmed sensor. A warning event is shown by a yellow indicator and an alarm event is shown by a red indicator. The "Reset Alarm" button will clear all alarms. Alarm handling is disabled when the "Disable Alarms" box is checked.

\section{SUMMARY}

CAVIS was specifically designed to minimize the labor, time, and radiation exposure associated with SNM inventories. It is a virtually passive sensor system designed to continuously monitor stored nuclear (radioactive) materials. CAVIS uses fiber optic and solid state sensors to verify item weight, temperature, gamma flux, relative enrichment, neutron flux (plutonium), location, and motion. Any change in these attributes provokes an immediate response to the appropriate alarm system(s).

CAVIS is a completely integrated system capable of remotely verifying radioactive material attributes stored in a variety of configurations. These include contaminated wastes, reactor fuel elements, reactor by-products, or treaty controlled nuclear materials.

The system as developed can reduce monitoring costs and provide a quick (100\%) inventory of all items stored in a SNM vault. CAVIS meets or exceeds all current DOE requirements for inventorying SNM and is potentially adaptable to a variety of storage configurations (e.g., waste storage areas, emergency inventory verifications, etc...

\section{ACKNOWLEDGMENTS}

The authors would like to acknowledge the support of their sponsors: the Office of Safeguards and Security at the Department of Energy in Washington DC, and Margaret Morrow, George Cobham, and James Stout of Defense Programs Division at the Oak Ridge Y-12 Plant.

The authors also would like to acknowledge the contributions of Louis Thacker, who recently retired, for his work in developing the scintillator - photosensor solid state gamma detector.

\section{REFERENCES}

1. T. A. Gafford, Modular Storage Vault for SNM, 35th Annual Proceedings from Institute of Nuclear Materials Management. Vol. 23, July 1994, pp 263-267.

2. Z. W. Bell, R. L. Lawson, and C. D. Long, Evaluation of Smart Shelf Technologies, Oak Ridge Y-12 Plant, Report Y/DW-1342.

3. A. D. Bross and A. Pla-Dalmau, "Radiation Effects in Plastic Scintillators and Fibers," Proceedings of the International Conference on Calorimetry in High Energy .Physics, Fermi National Accelerator Laboratory, October 1990.

4. S. A. McElhaney and R. I. Vandermolen, "Two Dimensional Position-Sensitive Detectors for Small-Angle Neutron Scattering," ORNLTM-11557, pp. 16-28, 1990.

5. "Scintillating Tile/Fiber Calorimetry Development at FNAL." Nucl. Phys. B, 23A, pp. 92-99, 1991.

6. S. Suzuki, et. al., "PMTs of Superior Time Resolution, Wide Dynamic Range, and Low Cross-Talk Multi-Anode PMTs," or "Delay Line Readout of Microchannel Plates in a Prototype Position-Sensitive Photomultiplier Tube," Nuclear Instruments and Methods in Physics Research A302, pp. 105-112, 1991. 
APPENDICES 


\section{Appendix A: Screen Copies of the Software}

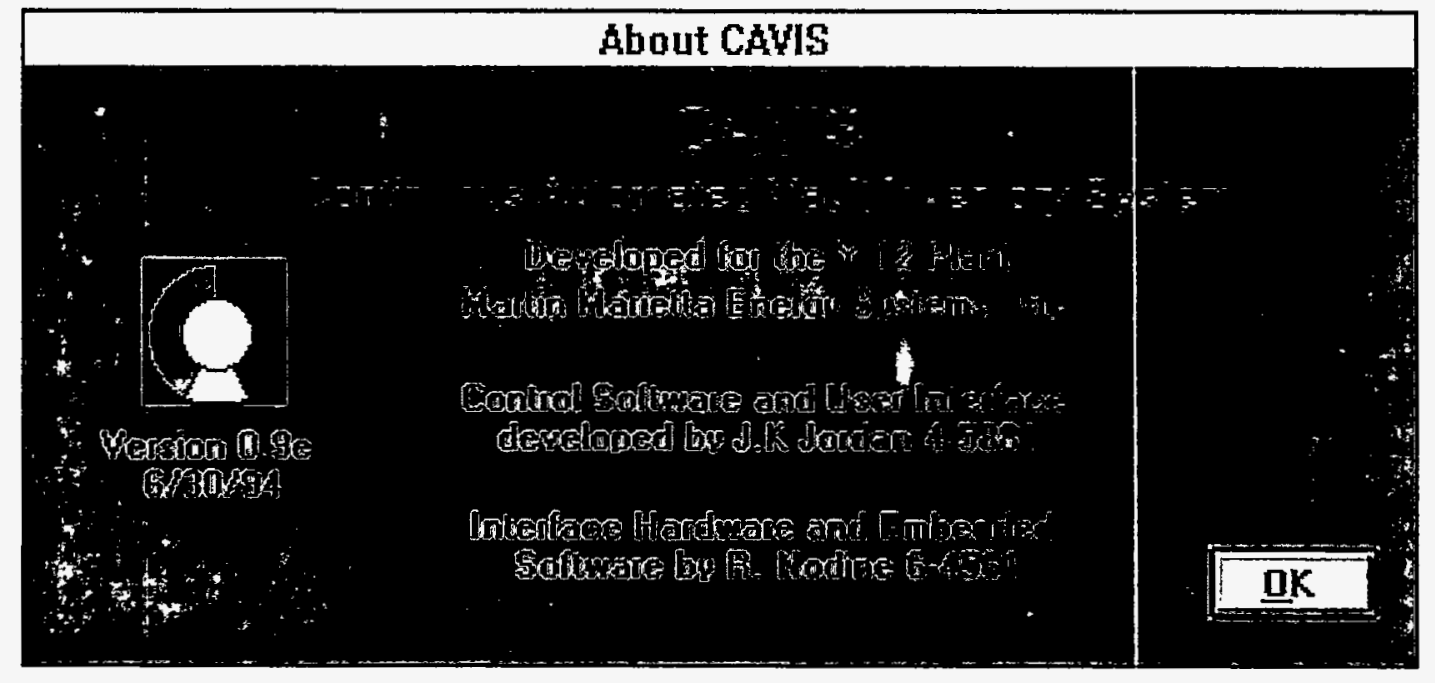

Screen1: Version and Author Information 


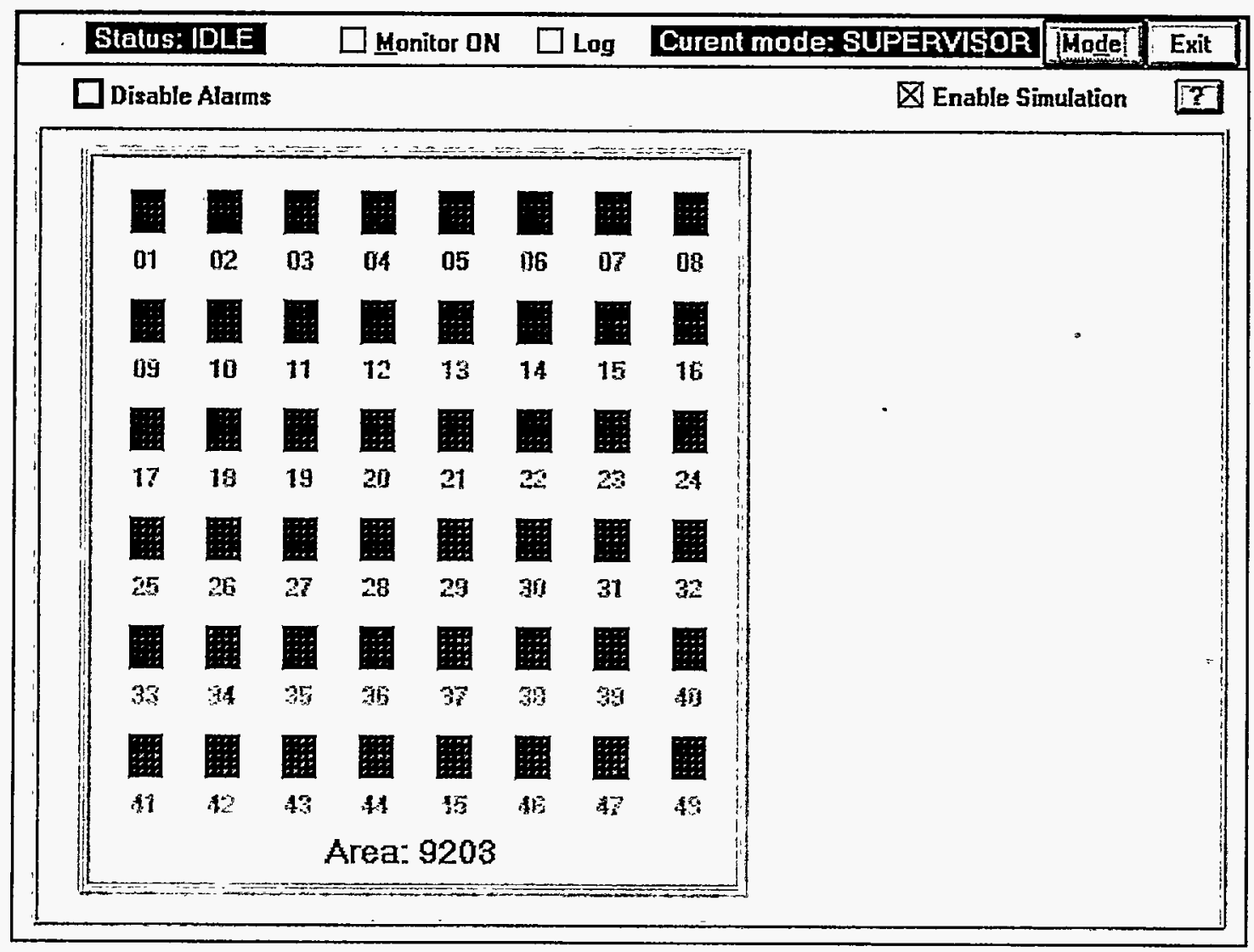

Screen2: Graphical representation of a Facility's MSV layout 


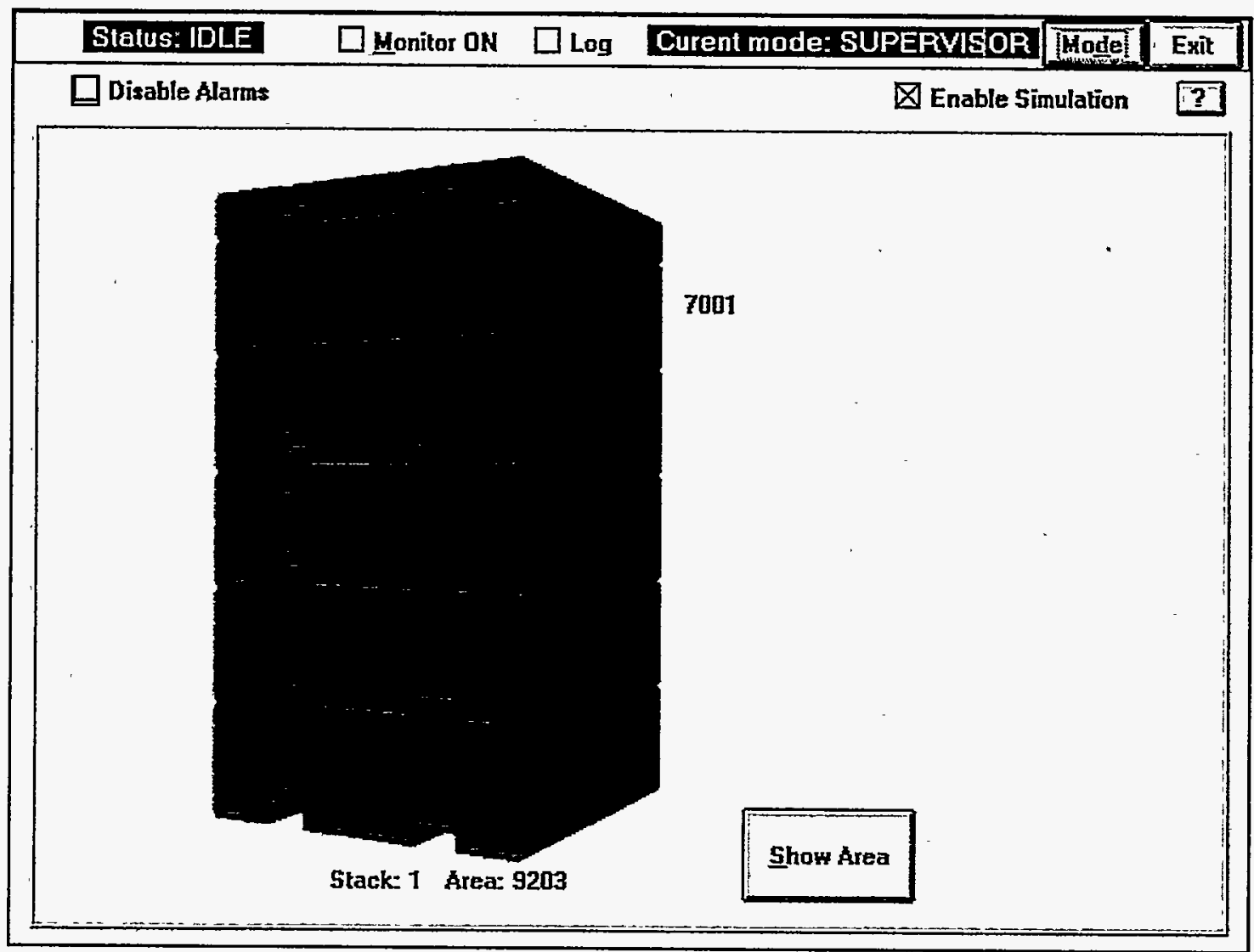

Screen3: Click on MSV in Screen2 and get representation of MSV stack 


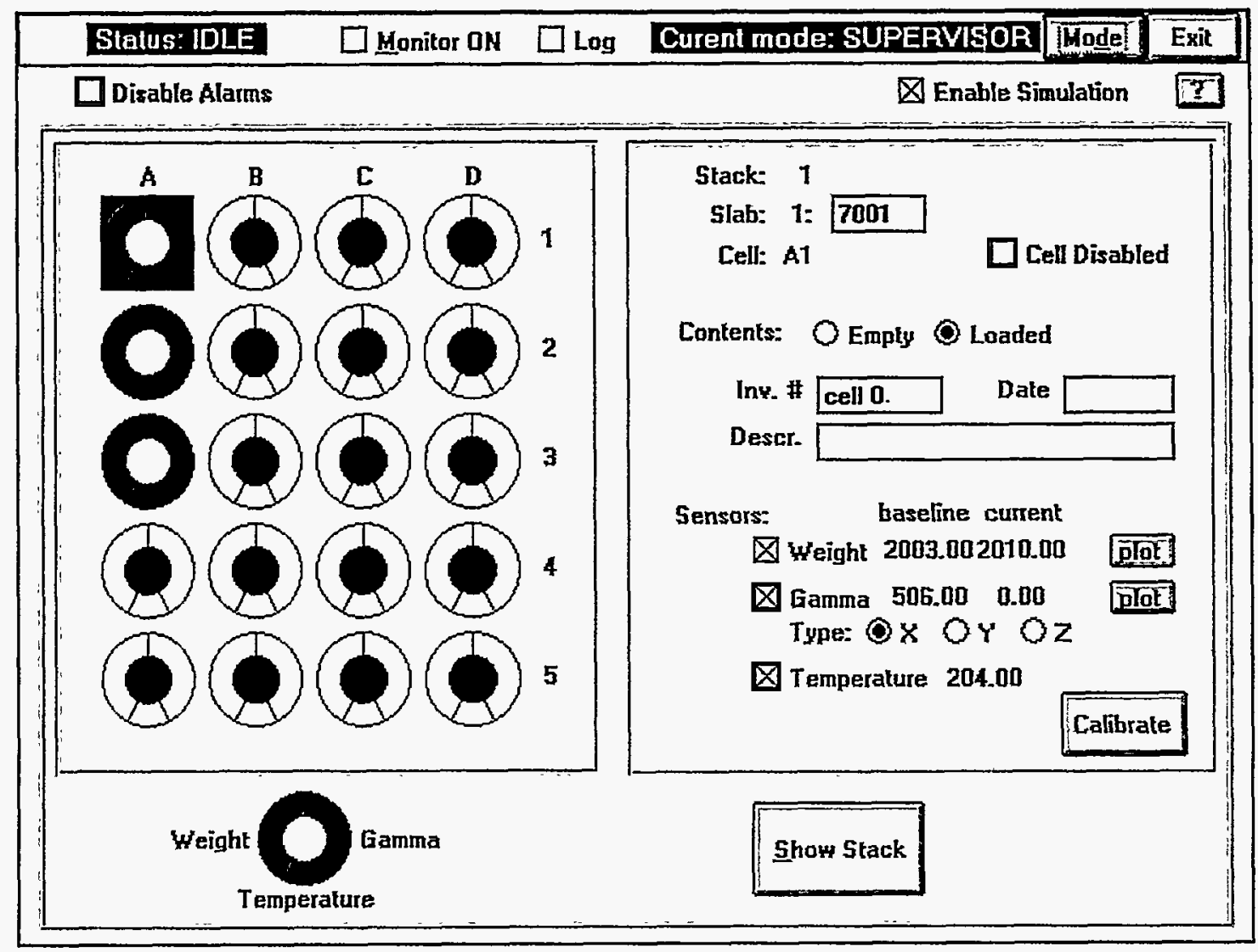

Screen4: Click on layer in Screen3 and get layer and sensor information on each stored item. 


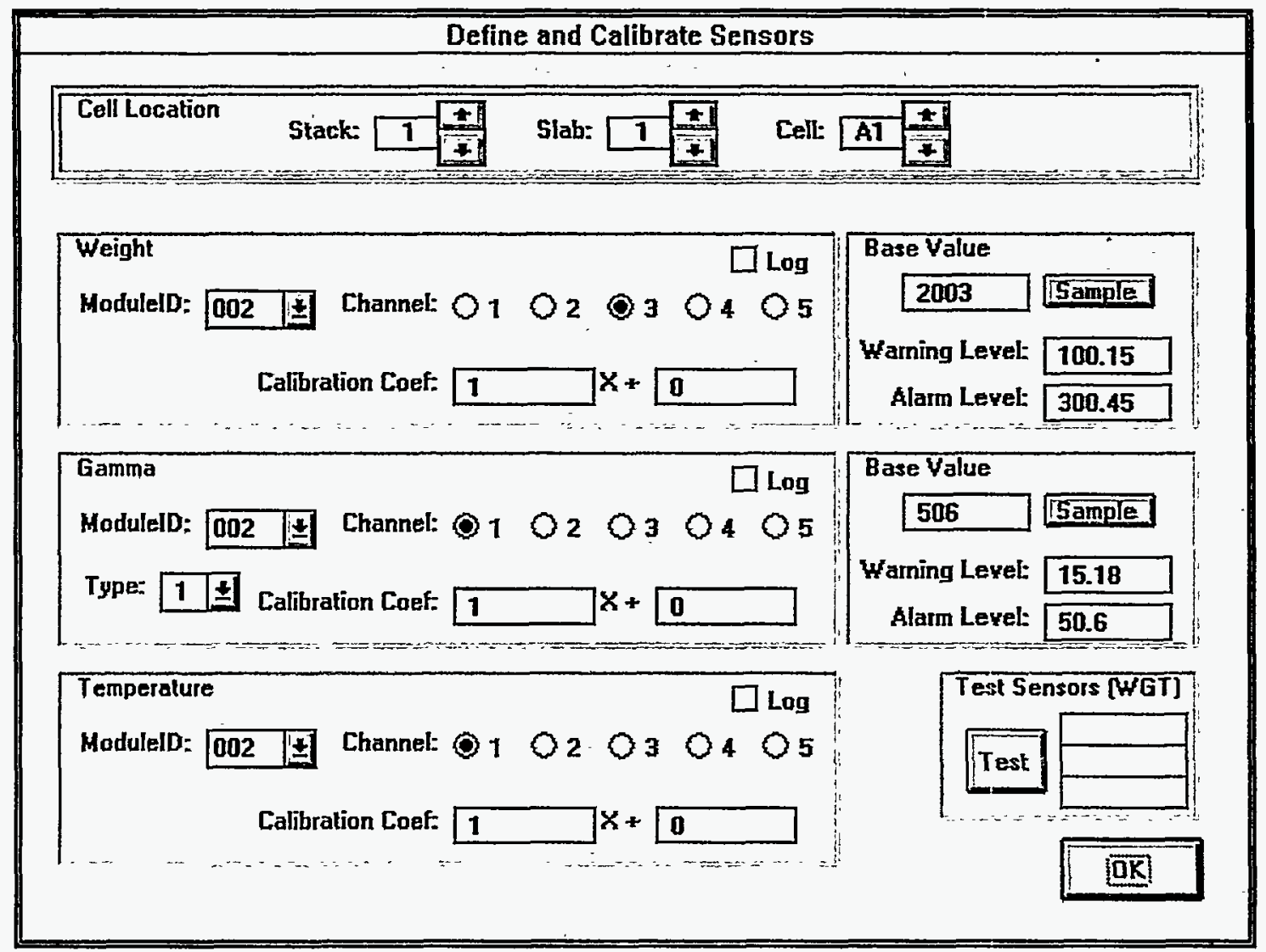

Supplementary Screen: Used when MSV is loaded to setup sensor information 


\section{Screen Indications when Sensor Alarms Occur}

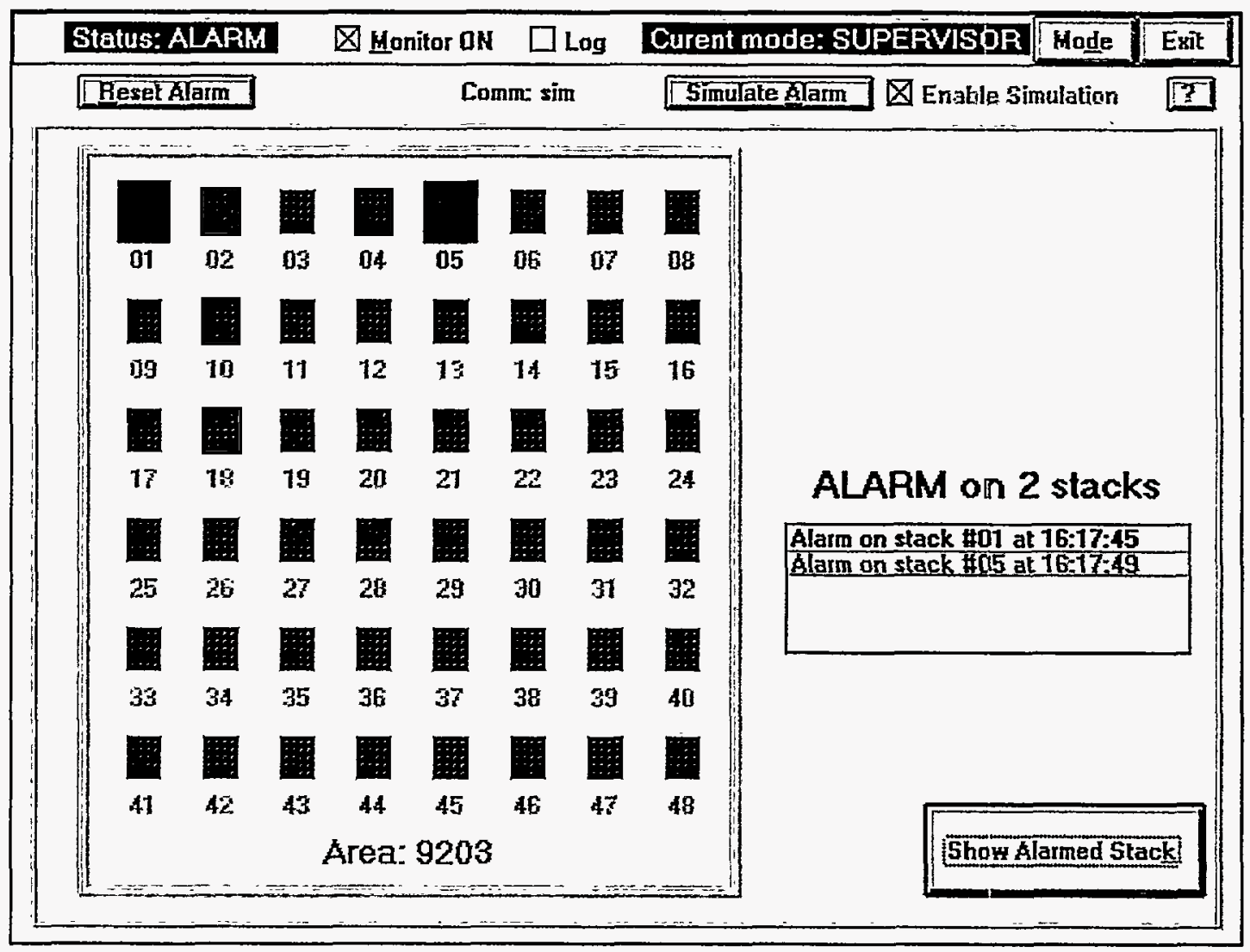

Screen2 with Alarm Indications 


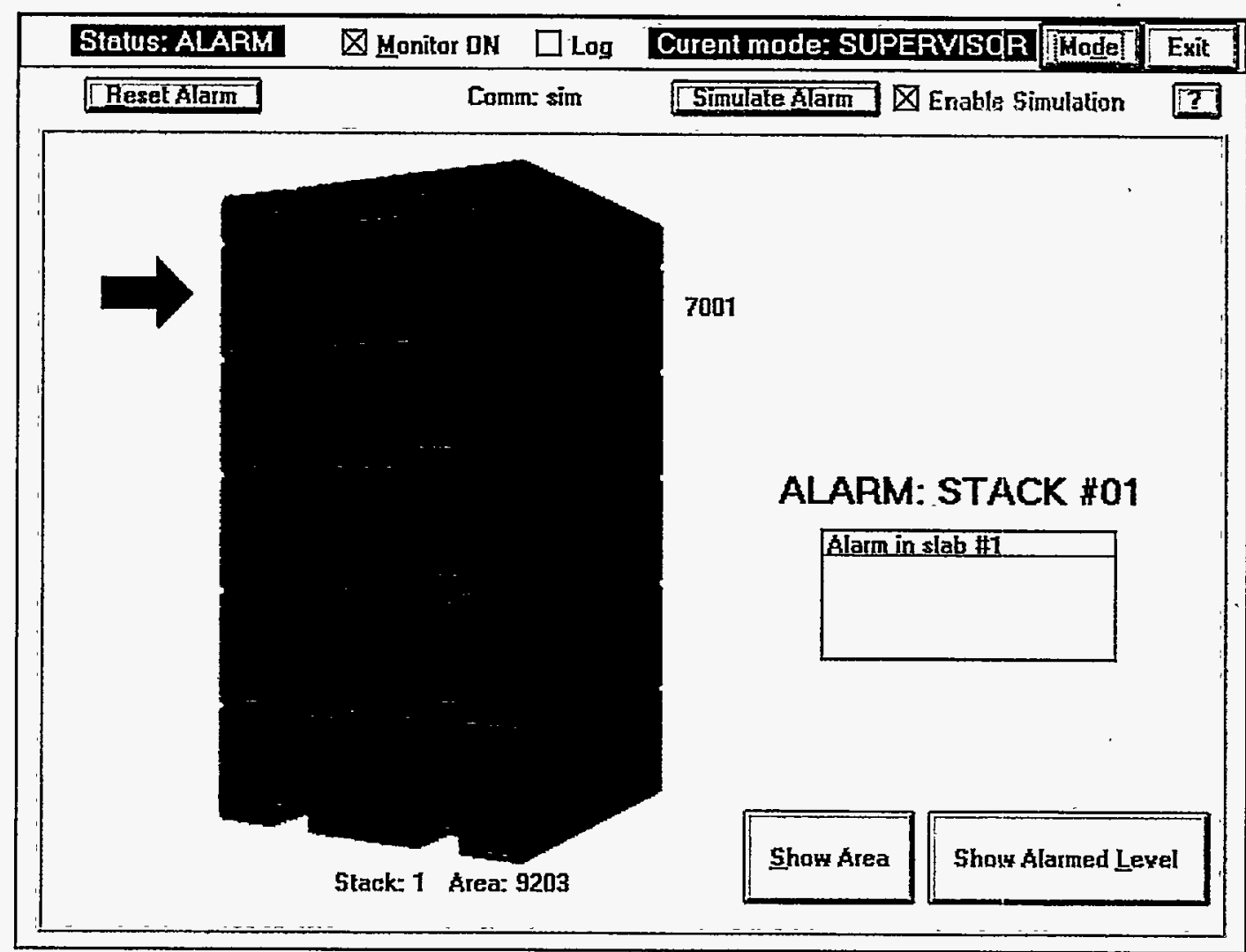

Screen3 with Alarm Indications 


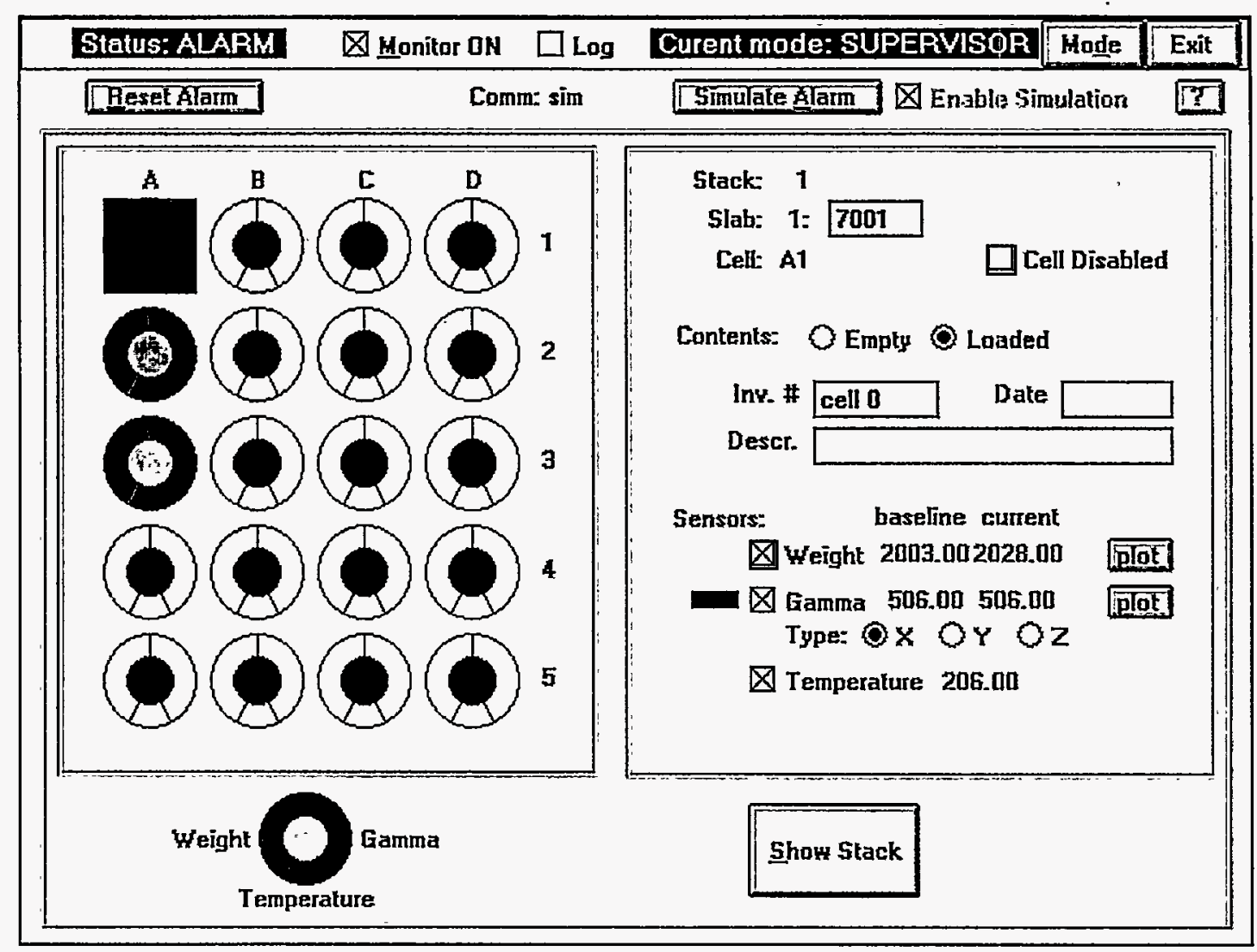

Screen4 with Alarm Indications 


\section{Distribution List}

Martin Marietta Energy Systems, Inc.

R. R. Abbott

M. A. Barham (5)

1652, MS-7350

M. L. Bauer

9113, MS-8206

D. Beck

Z. W. Bell

C. R. Bieber

D. B. Bopp

M. R. Bradshaw

R. W. Brandenburg

M. A. Buckner

T. R. Butz

R. N. Ceo

T. R. Chilcoat

S. R. Churnetski

3500 MS-6006

W. L. Clements

9203, MS-8084

9113, MS-8208

9710-3, MS-8212

1030, MS-7319

3500 MS-6006

9704-2, MS-8013

9212, MS-8081

9113, MS-8208

9202, MS-8097

9764, MS-8107

R. J. Collins

C. W. Coates

9204-2E, MS-8131

G. M. Cobham

9113, MS- 8208

9204-2, MS-8131

S.W. Combs

9119, MS-8233

9113, MS-8206

9624, MS-8222

K. H. Cooper

9113, MS-8207

S. O. Cox

9113, MS-8206

M. H. Ehinge

9113, MS-8206

D. R. Everitt

9113, MS-8207

B. T. Fowler

9119, MS-8233

G. M. Fuller

9710-2, MS-8212

T. A. Gafford (5)

9113, MS-8207

G. D. Hackett

9113, MS-8208

R. C. Hagenauer

1030, MS-7319

1024, MS-7325

7601, MS-6304

D. C. Haley

W. R. Hamel

7601, MS-6304

3037, MS-6016

J. T. Hargrove

1037, MS-7318

9119, MS-8233

W. H. Hopwood, Jr.

3500, MS-6006

D. P. Hutchinson

9212, MS-8193

N. C. Jessen, Jr.

I. W. Jeter

9624, MS-8222

1220 , MS-7280

9116, MS-8218

R. M. Keyser

9203, MS-8084

K. A. Kitzke

105MIT, MS-6495

F. M. Kovac

9212, MS-8193

J. A. Kreykes

9731, MS-8175

A. K. Lee/DOE-OSTI (2)

A. P. Malinauskus

1001, MS-7172 

L. C. Maxey
9102-2, MS-8039
B. K. Mattie
9624, MS-8222
S. McKenney
9113, MS-8206
S. A. Meacham
900TCB, MS-7606
S. G. Melton
9212, MS-8194
J. T. Mihalczo
B. W. Moran (20)
9113, MS-8206
M. K. Morrow
9704-2, MS-8016
J. D. Muhs
K-1220, MS-7280
R. E. Mulkey
9720-5, MS-8144
R. N. Nodine
3606, MS-6003
G. Patterson
G. L. Pfennigwerth
9212, MS-8194
C. A. Pickett (40)
9203, MS-8084
J. E. Powell
9116, MS-8098
A. W. Riedy
R. C. Riepe
1030, MS-7312
M. A. Simpson
9202, MS-8097
3500 MS-6006
C. E. Sliski
9212, MS-8194
D. B. Smith
S. E. Smith
R. L. Smith
K-1220, MS-7280
9212, MS-8194
S. G. Snow
9203, MS-8084
J. E. Stone
9624, MS-8222
9113, MS-8207
E. Stumpfl
R. G. Taylor
T. H. Thrasher
9202, MS-8097
W. H. Thompson, Jr.
C. R. Turner
9119, MS-8233
R. Upchurch
9113, MS-8206
9720-5, MS-8144
C. E. Walker
831TCB, MS-7606
R. L. Walker
9203, MS-8084
9720-6, MS-8042
P. R. Wasilko
J. M. Whitaker
9113, MS-8206
J. A. Williams
3500 MS-6010
Y-12 Central Files
9711-5, MS-8169

Department of Energy - Oak Ridge Operations

PO Box 2001

Oak Ridge, TN 37831

B. Cochran

D. Dunnam

R. Green

H. Heckman

G. Proco (5)

R. J. Spence

J. Ware 
Department of Energy - Washington D.C.

D. W. Crawford (5)

Maurice W. Daugherty

W. F. Hensley (5)

C. Pocratsky

Michelle Smith

C. D. Smith

Wendy Smoot (5)
NN-512.4

EM-15 CXXI

NN-512.4

NN-513.4

$\mathrm{NN}-513.4$
Washington, DC 20585

Germantown, MD 20874

Washington, DC 20585

Washington, DC 20585

Washington, DC 20585

Washington, DC 20585

DOE - Complex

Mason \& Hanger - Pantex

PO Box 30020

Amarillo, TX 79109

Rubin McGilvary

Los Alamos National Laboratory

PO Box 1663

Los Alamos, NM 87544

Justin E. Doak

Lynn A. Foster

Benny Martinez

Cheryl Rodriguez

Gary M. Weber

Andrew Zardecki

Los Alamos National Laboratory

PO Box 503

Los Alamos, NM 87544

Charlene Douglass

G. Eccleston

Norbert Ennslin

Earl Horley

Larry Parker

Pat Rood

Phylis Russo

Greg Sheppard

Jim Sprinkle

Savannah River Plant (SRP)

PO Box 616, 305-A Aiken, SC 29808

E. P. Maddux

Department of Energy - Chicago, Illinois

9800 S, Cass Avenue

Argonne, Il 60439

D. T. Baran

C. D. Bingham

Francis Healy 
Rod Martin

Michael Soriano

Sandia National Laboratories

PO Box 5800

Albuquerque NM 87185

Janet S. Ahrens

Michael J. Bensen

Ruth A. Duggan

James Foesch

S. C. Gray

Rebecca Horton

Kent Maclntyre

Ronald Moya

William K. Paulus

Lee Schoeneman

Mark Snell

Ivan Waddopps

Lawrence Livermore National Laboratory

PO Box 808,

Livermore, CA 94551

Richard C. Baxter

Michele A. Bergman

Richard J. Certo

Gregory E. Davis

David S. Fortney

Judy Lim

David McIntosh

Michael P. O'Brien

Sharon A. Snowden

R. Scott Strait

C. V. Turner

Richard VanSlyke

Amie Warshawsky

Don L. Wentz

Rick Wilson

Rocky Flats Plant

PO Box 464

Golden, CO 80402-0464

John A. Lynkiewicz

Joseph A. Jakubowski

Battelle - Pacific Northwest Laboratory

MS-K8-58

Richland, WA 99352

Kenneth R. Byars 